MODELING OCEAN, RAIL AND TRUCK TRANSPORTATION FLOWS TO SUPPORT POLICY ANALYSIS

\author{
A Dissertation \\ Presented to the Faculty of the Graduate School \\ of Cornell University \\ In Partial Fulfillment of the Requirements for the Degree of \\ Doctor of Philosophy
}

by

Hao Wang

August 2018 
(C) 2018 Hao Wang 


\title{
MODELING OCEAN, RAIL AND TRUCK TRANSPORTATION FLOWS TO SUPPORT POLICY ANALYSIS
}

\author{
Hao Wang, Ph. D. \\ Cornell University 2018
}

Freight transportation represents about $9.5 \%$ of GDP in the U.S., it is responsible for about $8 \%$ of greenhouse gas emissions and supports the import and export of about 3.6 trillion in international trade. It is therefore important that the national freight transportation system is designed and operated efficiently. Hence, this dissertation develops a mathematical model to estimate international and domestic freight flows across the ocean, rail and truck modes, which can be used to study the impacts of changes in our infrastructure, as well as the imposition of new user fees and changes in operating policies. The model integrates a user equilibrium-based logit argument for path selection with a system-optimal argument for rail network operations. This leads to the development of a unique solution procedure that is demonstrated in a large-scale analysis focused on all intercity freight and U.S export/import containerized freight. The model results are compared with the reported flow volumes. The model is applied to two case studies: (1) a disruption of the seaports of Los Angeles and Long Beach (LA and LB) similar to the impacts that would be felt in an earthquake; and (2) implementation of new user fees at the California ports. 


\section{BIOGRAPHICAL SKETCH}

Hao Wang was born in Changchun, in northeastern city of China. He holds a Bachelor of

Engineering from Tongji University, Shanghai, and a Master of Engineering in Cornell

University. His doctoral studies focus on Transportation Engineering. 
To my family and friends 


\section{ACKNOWLEDGMENTS}

This is an incredible journey at Cornell in which I am endowed with an enormous amount of support, love, encouragement, and freedom throughout these five years of study. I have been touched by so many ways, so many earnest professors, and so many excellent friends.

First and foremost, I would like to offer my sincere gratitude to Professor Linda K. Nozick. She is an extraordinary supervisor both in academic and in life. Her happiness and endless energy touched me deeply in the heart. Whenever I had difficulty with my research, she was always there, and could always help me out, so without her help, I can't even think about this research can be done. Her endless encouragement and constant faith are rocks in my heart whenever I encounter difficulty. I have a deep sense of pride to be instructed by her so closely.

I am also grateful to my Committee member Professor Ricardo Alvarez Daziano and Oliver Gao. They helped a lot throughout these years.

Last but not least, I would like to thank my parents for their tremendous love and support. 


\section{TABLE OF CONTENTS}

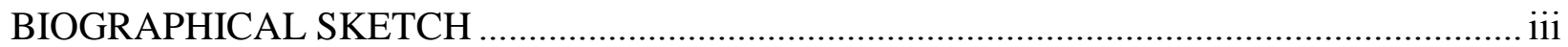

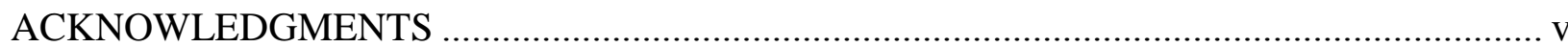

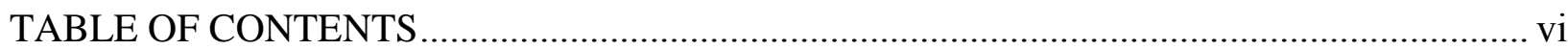

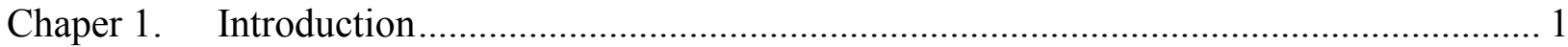

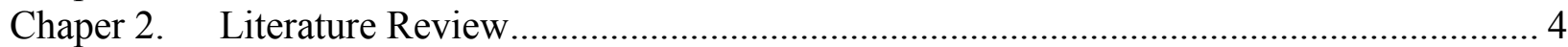

Chaper 3. Multi-product assignment model formulations........................................................ 7

3.1 Upper level model formulation and network ……………...................................... 8

3.2 Lower Level Rail Traffic Assignment Optimization Problem...................................... 16

Chaper 4. Solution Procedure.......................................................................................... 18

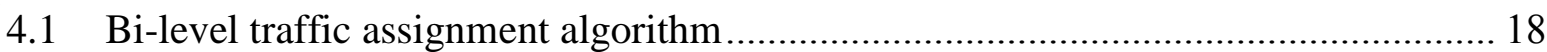

4.2 Computing $\boldsymbol{C r}$ (expected rail costs by O-D pair) ................................................... 19

Chaper 5. Model calibration ............................................................................................. 21

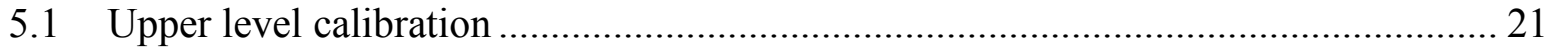

5.2 Lower level illustration and calibration.................................................................... 25

Chaper 6. Comparison of SO and UE link assignment in the rail network............................. 28

Chaper 7. Capability of the model and its applications ............................................................ 31

7.1 Example 1: Closure of the Ports at Los Angeles and Long Beach............................... 31

7.2 Example 2: Pricing changes in California................................................................ 34

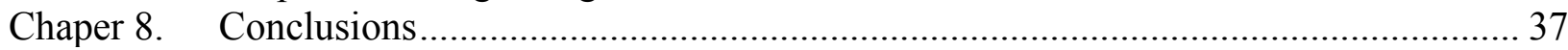

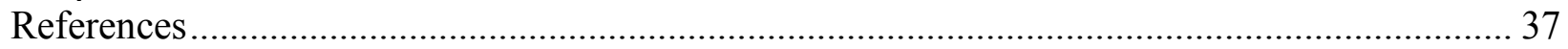




\section{Chaper 1. Introduction}

In 2010, on average, each person in the U.S. is associated with about 55.2 tons of goods that must be transported. Once distances are considered, the per-person derived demand for freight transportation is about 17,957.4 ton-miles (Bureau of Transportation Statistics, 2013). This clearly results in substantial freight transportation costs, which are in the order of $9.5 \%$ of GDP. It is also worth noting that congestion costs to the trucking industry were about $\$ 63$ billion in 2015. Beyond the financial costs, the total transportation system was responsible for $27 \%$ of greenhouse gas emissions, among them 28.5\% was from freight transportation in 2015(Bureau of Transportation Statistic, 2015). More importantly, the growth rate in emissions from freight sources has been more than six times as fast as that for passenger travel since 1990. Finally, substantial portions of our infrastructure are in earthquake and hurricane-prone regions. For instance, U.S. Geological Survey (USGS ) reports that there is more than a $50 \%$ chance of a magnitude 7.0 earthquake in the San Francisco Bay region within the next 30 years (Aagaard, et al, 2016).

The import and export of containerized and bulk commodity domestic freight is a vital part of the U.S economy. Across the nearly $\$ 4$ trillion per year of trade since 2014, waterborne transportation carried about $44.2 \%$, as measured by value and $71.6 \%$ by weight. Further, the ports of LA and LB together handled about $40-44 \%$ of the total TEUs imported and exported and this dominance has persisted for over 20 years though the expansion of the Panama Canal in 2016 provided an improved alternative for shipments from Asia destined for the east coast. Since international trade is expected to grow at about 3.4\% per year through 2040 (Bureau of 
Transportation Statistics, 2015), the volumes on already congested freight corridors inside the U.S. will increase. For example, several of the rail corridors in the Southern California area are operating at Level of Service E, which is defined as very heavy train flow with very limited capacity to accommodate maintenance and recovery from incidents (AAR, 2007).

It is also worth noting that a substantial portion of freight transportation is multimodal; that is, for a single shipment, more than one mode of transport is used. For U.S. imports and exports, this is obvious because exports are brought to the port via rail or truck and imports must depart the port area via either rail or truck. Furthermore, domestic containerized rail is generally combined with a drayage operation on both ends. Some bulk waterway traffic uses rail for some portion of the movement as well. The Federal Highway Administration (2016) projects that the value of multimodal transportation is forecasted to grow at about 2.4\% per annum until 2045. This dissertation develops a multimodal model of freight transportation where the goal of the shippers is to minimize total logistics costs as given by a logit model. This leads to an equilibrium based representation of traffic flows across the networks. We explicitly represent containerized ocean traffic to and from the continental U.S., U.S. rail traffic (containerized and bulk), and commercial truck traffic. Our research extends the model described in Jones et al (2011). There are two key advancements in this dissertation. First, we integrate a system optimal representation for the flow of rail traffic across the rail network. Since Jones et al (2011) focused on user equilibrium as the basis of all flows in the network, they developed an algorithm for user equilibrium that allowed capacity constraints on links. In contrast, our integration of a system optimal routing policy in the rail network creates a bi-level modeling structure. Second, we explicitly represent all traffic on the rail network. Jones et al (2011) focused on containerized 
import and export traffic only and assumed that the costs associated with rail traffic by link were static. Thus, a single rail path between each traffic analysis zone and the port was sufficient. In contrast, we represent all rail traffic and therefore the model explicitly considers congestion in the identification of the system optimal flow pattern in the rail network.

The dissertation is organized as follows. First, the relevant literature is reviewed. Second, the model formulation and the solution procedure are given. The calibration of the model is then presented. Model flows and costs based on system optimal and user equilibrium assumptions for the operating principle in the rail network are compared. Fourth, two applications of the model are illustrated; the closure of the ports of LA and LB, and the implementation of port access fees at California ports. Finally, opportunities for future research are discussed. 


\section{Chaper 2. Literature Review}

We build on a rich literature of international, national and regional multimodal freight flow models. These models address strategic questions and include either the entire or a significant part of a national freight transportation system. These models can be largely classified into two groups (Crainic and Gilbert, 1997): spatial price equilibrium models and network models. The core ideas behind these two classes of models differ substantially. Spatial price equilibrium models endogenously match production locations and consumption locations and explicitly include product pricing-based supply and demand relationships (Labys et al.(1997); Nagurney et al. (2002)). Given their focus on prices, they use a more "high level" representations of the physical networks.

The emphasis of network models is generally opposite to those of spatial price equilibrium models. Rather than focus on pricing, they focus on a more complete representation of the network facilities and the assignment of goods to those facilities. Unlike spatial price equilibrium models, the origin and destination (O-D) table is usually exogenous in network models. There isn't a separately identifiable representation for shippers or individual carriers (Guelat et al. (1990); Jourquin and Limbourg (2006); Fan et al. (2010); Jones et al. (2011)). In some network models, there are distinct shippers and carriers but in those models each carrier has their own network and that carrier may or may not share the same facilities with others (Harker and Friesz (1985); Friesz et al. (1986); Joaquin et al. (2003); Agrawal and Ziliaskopoulos (2006)). Also, where individual shippers are explicitly represented, they make decisions based on the schedule, price, and service quality (percentage of product loses, the variance of travel time, etc.) provided by carriers (Joaquin et al. (2003)). Where carriers are 
explicitly represented, they transport goods so as to maximize their own benefit (Agrawal and Ziliaskopoulos (2006)).

The representation of the mechanisms by which freight moves from one mode to another varies substantially across network models. Sometimes (Guelat et al. (1990); Crainic et al. (1990)), transfers are represented implicitly by a pair of arcs, entering and leaving the transfer node, where mode transfer is possible. Such representation also permits one to restrict certain commodities to subsets of modes. In some other models (Jones et al. (2011); Ham et al. (2005)), an explicit logit model is used for mode selection at specific facilities (ports, transfer location) to handle transfers.

The model described in this dissertation is a network model, where shippers and carriers are not distinct actors in the decisions made. Table.1 summarizes the most relevant network focused models. Origins and destinations correspond to relatively large geographical areas, which aggregate all the individual shippers for the same product. The O-D table for each commodity is assumed to be determined from other sources. We assume the path and mode selection for each shipment is performed so as to minimize the generalized cost of the transportation for that shipment. This assumption leads to an equilibrium assignment across a "high level" network. The logit model is adopted to handle mode selection and transfer, which is similar to Jones et al. (2011) and Ham et al. (2005). However, this research also includes a relatively detailed representation of the rail network including prohibitions of specific commodities on individual facilities. The rail network is modeled separately, in contrast to most of the literature mentioned above, integrates the rail and road network together. Hence, this dissertation integrates a user 
equilibrium-based logit argument for path selection (for shipments) with a system- optimal

argument for rail network operations. This leads to a bi-level modeling structure that necessitates

the use of a unique solution procedure. The formulation and solution procedure are demonstrated

in a large-scale analysis focused on all intercity domestic freight and U.S export/import

containerized freight.

Table.1. Illustrative Network Flow Models

$($ RO = Road; $R=$ Rail; $S=$ Ship; En. = Endogenous; Ex. = Endogenous $)$

\begin{tabular}{|c|c|c|c|c|c|c|c|c|}
\hline Reference & $\begin{array}{l}\text { Multi- } \\
\text { commo } \\
\text { dity }\end{array}$ & Mode & $\begin{array}{l}\text { Discrete } \\
\text { Choice } \\
\text { Model }\end{array}$ & $\begin{array}{c}\mathrm{O} / \mathrm{D} \\
\text { matrix }\end{array}$ & $\begin{array}{l}\text { Assign- } \\
\text { ment } \\
\text { Method }\end{array}$ & $\begin{array}{l}\text { Capacit } \\
\text { y Limits }\end{array}$ & $\begin{array}{l}\text { Ind. } \\
\text { Links }\end{array}$ & Insights \\
\hline $\begin{array}{l}\text { Guelat et al. (1990) } \\
\text { Crainic et al. (1990) }\end{array}$ & Yes & $\begin{array}{l}\mathrm{RO}, \mathrm{R}, \\
\mathrm{S}\end{array}$ & No & Ex. & $\mathrm{SO}$ & No & No & $\begin{array}{l}\text { Truck still offers the most rapid } \\
\text { alternative, even with } \\
\text { construction of a new rail line } \\
\text { in San Francisco. }\end{array}$ \\
\hline $\begin{array}{c}\text { Jourquin and Beuthe (1996) } \\
\text { Beuthe et al. (2001) } \\
\text { Jourquin and Limbourg } \\
(2006)\end{array}$ & Yes & $\begin{array}{l}\mathrm{RO}, \mathrm{R}, \\
\mathrm{S}\end{array}$ & No & Ex. & SO & No & Yes & $\begin{array}{l}\text { Railway transports appear } \\
\text { more sensitive to cost variation } \\
\text { in road transport than inland } \\
\text { waterways. }\end{array}$ \\
\hline $\begin{array}{c}\text { Agrawal and Ziliaskopoulos } \\
\text { (2006) }\end{array}$ & Yes & $\mathrm{RO}, \mathrm{R}$ & No & Ex. & $\begin{array}{l}\text { UE \& } \\
\text { SO }\end{array}$ & Yes & No & $\begin{array}{l}\text { Shipments with higher delay } \\
\text { costs tend to be shipped using } \\
\text { faster modes. }\end{array}$ \\
\hline Jones et al. (2011) & No & $\begin{array}{l}\mathrm{RO}, \mathrm{R}, \\
\mathrm{S}\end{array}$ & Yes & Ex. & UE & Yes & Yes & $\begin{array}{l}\text { Other ports have capacity for } \\
\text { goods disrupted by lack of rail } \\
\text { access at LA and LB. Fees are } \\
\text { effective to incentive re- } \\
\text { routing. }\end{array}$ \\
\hline Fan et al. (2010) & No & $\begin{array}{l}\mathrm{RO}, \mathrm{R}, \\
\mathrm{S}\end{array}$ & No & Ex. & $\mathrm{SO}$ & Yes & Yes & $\begin{array}{l}\text { \$135/TEU in cost reduction if } \\
\text { capacity at Houston is } \\
\text { expanded. }\end{array}$ \\
\hline Tavasszy et al. (2011) & No & $\begin{array}{l}\mathrm{RO}, \mathrm{R}, \\
\mathrm{S}\end{array}$ & No & Ex. & $\mathrm{UE}$ & No & Yes & $\begin{array}{c}\text { Slow-steaming encourages } \\
\text { sea-sea transshipment } \\
\text { operations at hubs. }\end{array}$ \\
\hline Maia and Couto (2013) & No & $\mathrm{RO}, \mathrm{R}$ & Yes & Ex. & SO & Yes & Yes & $\begin{array}{l}\text { Compared improvement of } \\
\text { existing links and construction } \\
\text { of new ones. }\end{array}$ \\
\hline Ishfaq (2013) & No & $\mathrm{RO}, \mathrm{R}$ & No & Ex. & $\mathrm{SO}$ & No & Yes & $\begin{array}{l}\text { Intermodal freight has both } \\
\text { cost advantages and } \\
\text { competitive transit times over } \\
\text { road under disruption. }\end{array}$ \\
\hline Uddin and Huynh (2015) & Yes & $\mathrm{RO}, \mathrm{R}$ & No & Ex. & UE & No & No & $\begin{array}{c}\text { Synthetic network used for } \\
\text { analysis. }\end{array}$ \\
\hline $\begin{array}{l}\text { Mahmassani et al. (2007) } \\
\text { Zhang et al. (2008) } \\
\text { Miller et al. (2009) }\end{array}$ & Yes & $\begin{array}{l}\mathrm{RO}, \mathrm{R}, \\
\mathrm{S}\end{array}$ & No & Ex. & DTA & Yes & Yes & $\begin{array}{c}\text { Rail infrastructure } \\
\text { improvements can substantially } \\
\text { improve the attractiveness of } \\
\text { rail. }\end{array}$ \\
\hline Abadi et al. (2016) & No & $\mathrm{RO}, \mathrm{R}$ & No & En. & DTA & Yes & Yes & $\begin{array}{l}\text { The proposed control system } \\
\text { can reduce traffic congestion } \\
\text { and travel times. }\end{array}$ \\
\hline $\begin{array}{c}\text { Harker and Friesz (1985) } \\
\text { Harker(1986) } \\
\text { Friesz et al. (1986) }\end{array}$ & Yes & $\begin{array}{l}\mathrm{RO}, \mathrm{R}, \\
\mathrm{S}\end{array}$ & No & En. & $\mathrm{UE}$ & No & Yes & $\begin{array}{l}\text { Demonstrated with U.S. coal } \\
\text { freight that intuitive } \\
\text { predictions in complex systems } \\
\text { can be incorrect. }\end{array}$ \\
\hline Joaquin et al. (2003) & Yes & $\mathrm{RO}, \mathrm{R}$, & Yes & En. & UE \& & No & Yes & Carriers with lower \\
\hline
\end{tabular}




\begin{tabular}{|c|c|c|c|c|c|c|c|c|}
\hline & & S & & & SO & & & $\begin{array}{c}\text { transportation fares, carry more } \\
\text { shipments (tons). }\end{array}$ \\
\hline Ham et al. (2005) & Yes & RO,R & Yes & En. & UE & No & Yes & $\begin{array}{c}\text { Predicted commodity } \\
\text { shipments compare reasonably } \\
\text { well with the observed } \\
\text { commodity shipments. }\end{array}$ \\
\hline Wang and Nozick & Yes & $\begin{array}{c}\text { RO,R, } \\
\text { S }\end{array}$ & Yes & Ex. & $\begin{array}{c}\text { UE \& } \\
\text { SO }\end{array}$ & Yes & No & $\begin{array}{c}\text { SO rail reduces costs vs. UE. } \\
\text { Loss of LA and LB can be } \\
\text { accommodated. \$100 port fee } \\
\text { at California ports causes } \\
\text { traffic diversions for goods } \\
\text { bound for the eastern US. }\end{array}$ \\
\hline
\end{tabular}

\section{Chaper 3. Multi-product assignment model formulations}

This section develops a mathematical model that characterizes the equilibrium traffic assignment in the U.S. for containerized imports and exports, as well as for intercity freight transportation (i.e. full truckload and rail carload by commodity). We assume that a single shipment of nonbulk freight (full trailer/container) can be transported either by truck or by rail inside the U.S. but not both. In contrast, bulk freight (grain, coal, etc.) is assumed to always travel by rail inside the U.S.

We assume that shippers select modes and paths to minimize total logistics costs as given by a logit model. We assume that rail transport is operated by rail carriers as a single integrated rail network and that they assign traffic to this network consistent with a system optimal routing policy. The need to include two different "levels" of link assignment (shipper and rail carrier) necessitates the use of a bi-level structure. In the upper level model, shippers make mode and path choices in a "service network". When a shipment's path includes a highway or ocean segment, a physical path for those movements is identified in the upper level. If the path includes a rail movement, only the decision of the end points of that movement is identified in the upper level. In the lower level, the physical path for that portion of the movement is identified. The next subsection describes the upper level network and model formulation. The second subsection 
gives the lower level network and model formulation.

\subsection{Upper level model formulation and network}

We formulate the traffic assignment in the upper level as a general form of the equilibrium flow problem (with link capacity constraints) as follows:

Minimizes:

$$
\sum_{a} \int_{0}^{v_{a}} C_{a}(\omega) d \omega
$$

Subject to:

$$
\begin{gathered}
\sum_{k \in K_{m n}} f_{m n}^{k}=q_{m n} \quad \forall m, n \\
v_{a}=\sum_{m, n} \sum_{k \in K_{m n}} \delta_{m n}^{a k} f_{m n}^{k} \quad \forall a \\
0 \leq v_{a} \leq U_{a} \quad \forall a \\
f_{m n}^{k} \geq 0 \quad \forall m, n, k
\end{gathered}
$$

Where $v_{a}$ is the flow on link $a ; C_{a}\left(v_{a}\right)$ is the unit equilibrium cost on link $a ; q_{m n}$ is the volume needed to be transported from origin $m$ to destination $n ; K_{m n}$ is the set of the paths that connect the origin and the destination; $f_{m n}^{k}$ is the flow on path $k, k \in K_{m n} ; \quad \delta_{m n}^{a k}$ equals 1 if link $a$ is part of path $k$ from origin $m$ to destination $n$ and 0 otherwise; $U_{a}$ is the capacity of link $a$.

The mode selection decision is assumed to be made by the shippers. There are many factors that influence this decision, some of which are difficult to quantify. Hence, like other authors, we apply a logit choice model using generalized costs. We use this structure to empirically match mode split between rail and truck at each port. This is the same process used in Jones et al (2011) and is equivalent to Sheffi (1985). The logit model is given in Eq.(6). 


$$
q_{i j}^{r}=\frac{q_{i j}}{1+e^{\theta_{i j}\left(C_{i j}^{r}-C_{i j}^{t}-\varphi_{i j}\right)}}
$$

where $q_{i j}$ : total O-D flow from origin $i$ to destination $j ; q_{i j}^{r}$ : total rail flow from origin $i$ to destination $j ; C_{i j}^{r}$ : cost of using rail from origin $i$ to destination $j ; C_{i j}^{t}$ : cost of using truck from origin $i$ to destination $j ; \theta_{i j}$ : unit conversion parameter (estimated from data); $\varphi_{i j}$ : rail bias parameter (estimated from data). $\varphi_{i j}$ gives the relative distaste for rail on comparision to truck that is not the result of differences in costs. $\theta_{i j}$ gives the sensitivity of the choice between rail and truck to the difference in the cost (including the "costs" that stem from the rail bias parameter) of using the two modes. Eq.(6) can be manipulated so that (with $i, j$ subscripts suppressed):

$$
C^{t}=C^{r}+\frac{1}{\theta} \ln \left(\frac{q^{r}}{q-q^{r}}\right)-\varphi
$$

Thus, Eq.(7) can be viewed as the equilibrium condition between the generalized total costs of the two modes, $\left(C^{t}, C^{r}\right)$, as a function of the rail volume. In computing the total cost for import and export flows, the ocean voyage and the port costs are the same for both domestic rail and truck modes. The last two terms in Eq.(7) can be viewed as an "extra link" to use the domestic rail system. We adopt the language for this extra link of rail access link (Sheffi, 1985). Note: both $\theta$ and $\varphi$ are used for calibrating the rail access pseudo-cost function to match the observed mode split at port. Fig. 1. illustrates the rail access link between $\operatorname{port}_{i}$ and $e_{i}^{i m}$.

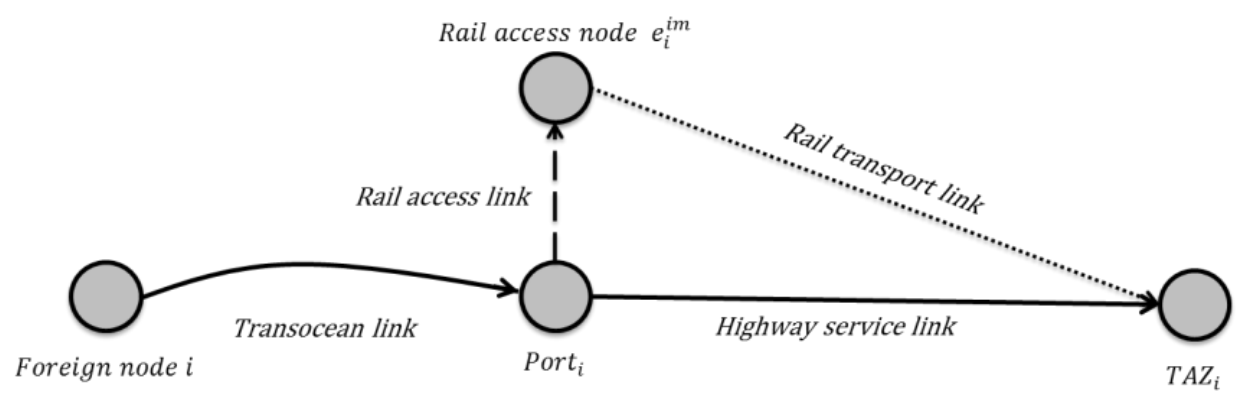

Fig. 1. Illustration of "rail access" link. 
While $\theta$ and $\varphi$ can be specified for each O-D pair, the data to perform this calibration is limited, hence we use a simplified network representation, as shown in Fig. 2. Hence, for all import flows from port $_{i}$ using rail, a single rail access link is used. Similarly, for all containerized exports leaving the U.S. via port ${ }_{i}$, a different rail access link is used. Since several ports have limitations that are directional (imports separate from exports) on how much freight can be transferred from the port (or to the port) to the rail network (from the rail network), we use these rail access links to impose these capacity constraints where they exist.

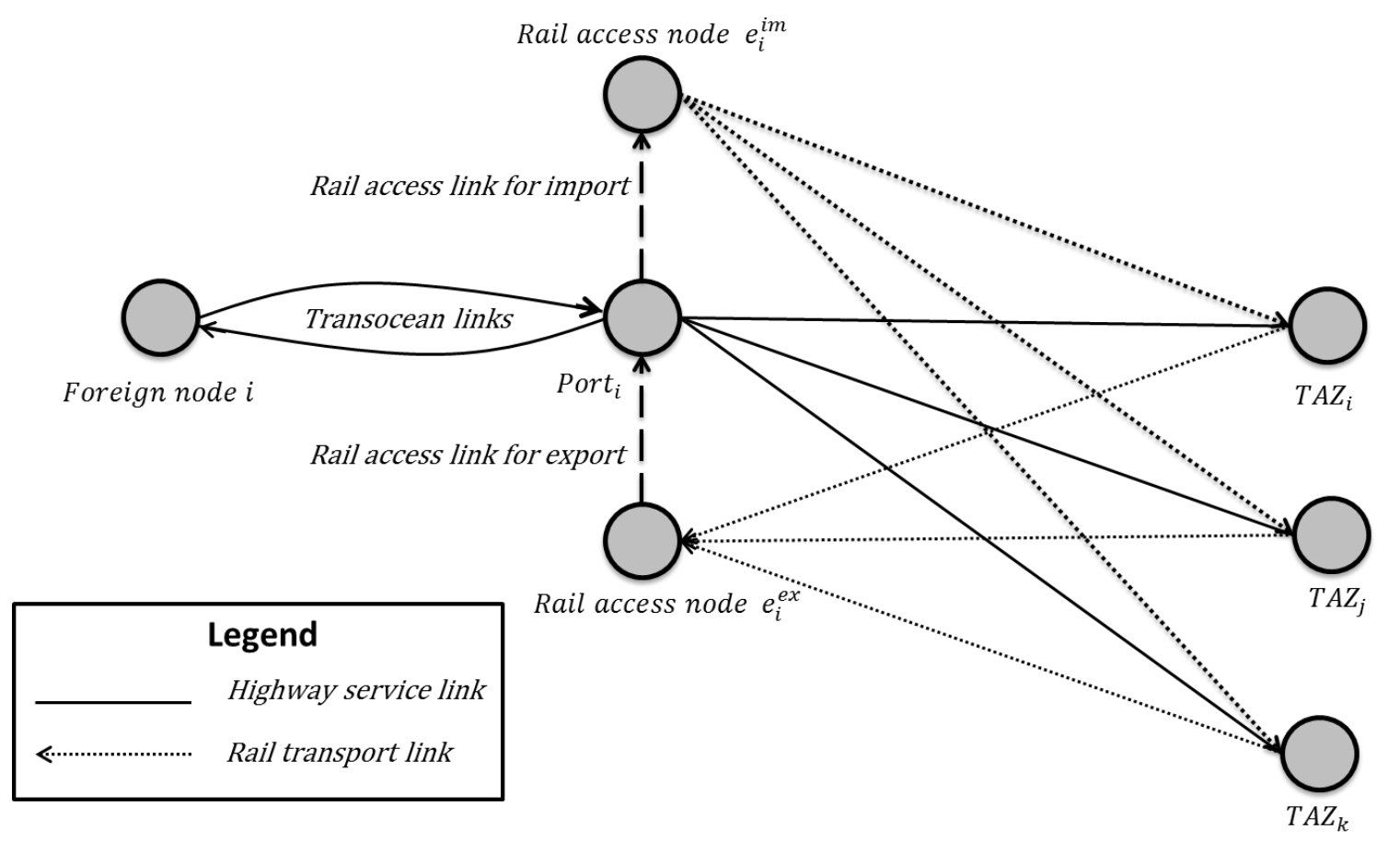

Fig. 2. One "rail access" link to multiple destinations.

The network that is input to the upper level model is essentially a service network. The network represents the mode and path characteristics, summarized by costs and capacities, available to the shipper. Fig. 3 illustrates this service network with a single foreign country, a single port and two traffic analysis zone (TAZs). It is easiest to understand how this network is constructed by focusing, in turn, on each type of shipment included in the model. These types are (1) U.S. 
imports, (2) U.S. exports, (3) containerized domestic, and (4) non-containerized shipments to be transported on the rail network.

For U.S. imports, each container originates in a foreign country and hence it enters the network via a node that represents that particular foreign country. For illustration, in Fig. 3, this node is labeled foreign node $i$. From that node, a transocean link is used to move the shipment to a U.S. port. In Fig. 3, this port is labeled port ${ }_{i}$. The port of entry to the U.S. is decided by optimization, but for the purposes of this example we assume it enters via port $_{i}^{a}$. Each U.S. port is represented by two nodes because: (1) the level of congestion (and therefore the resultant generalized cost on that link) at a port is a function of the total traffic (inbound and outbound); and (2) there is a fixed port capacity that the optimized port flows must not exceed. The volume to generalized cost function and the capacity constraint for a port is associated with the directed link that connects the two port nodes (port $t_{i}^{a}$ and port $t_{i}^{b}$ in Fig. 3) together. Both import and export flows will enter the port through port $i_{i}^{a}$ and exit the port throuth $\operatorname{port}_{i}^{b}$. From the U.S. port, the shipment either travels by highway or rail to its final destination. If the transport is by truck, because we do not represent congestion on the highway system, there is a single link (termed the highway service link) that connects the port of import with the destination TAZ. That link is associated with the generalized cost to move that shipment from the port to the destination using the lowest generalized cost path by truck. If the shipment is moved to its destination TAZ by rail, there is a rail access link and a rail transport link that connects the port to the destination TAZ. The rail transport link representes the lowest generalized cost from the port to the TAZ via rail. 
For export flows, a container enters the network via one of the TAZ nodes. For illustration, in Fig. 3 this node is labeled $T A Z_{i}^{\text {out }, c}$. The port of export is also a decision made by the optimization (same as for U.S. imports). In Fig. 3, we assume it uses port p $_{i}$ The container can either travel by truck or rail to enter the port via node port $_{i}^{a}$. If the travel is by truck, the highway service link is used. If the travel is by rail, the rail transport link is used via the rail access node, and the rail access link to the port. Once the container reaches the port, it uses the same port link as U.S. imports. Finally, the transocean link is used to move the shipment to its final destination, in this case, foreign country node $i$.

For containerized domestic traffic, the movements associated with a single container are illustrated using $T A Z_{i}$ and $T A Z_{j}$. Two direct links between $T A Z_{i}^{\text {out,c }}$ and $T A Z_{j}^{\text {in }}$ represent the truck and rail services available. The optimization model selects which mode to use. Fig. 3 also illustrates the links used for non-containerized traffic between $T A Z_{i}$ and $T A Z_{j}$. Node $T A Z_{i}^{\text {out, nc }}$ is the origin of the shippment, through the rail transport link to reach the destination node $T A Z_{j}^{\text {in }}$. 


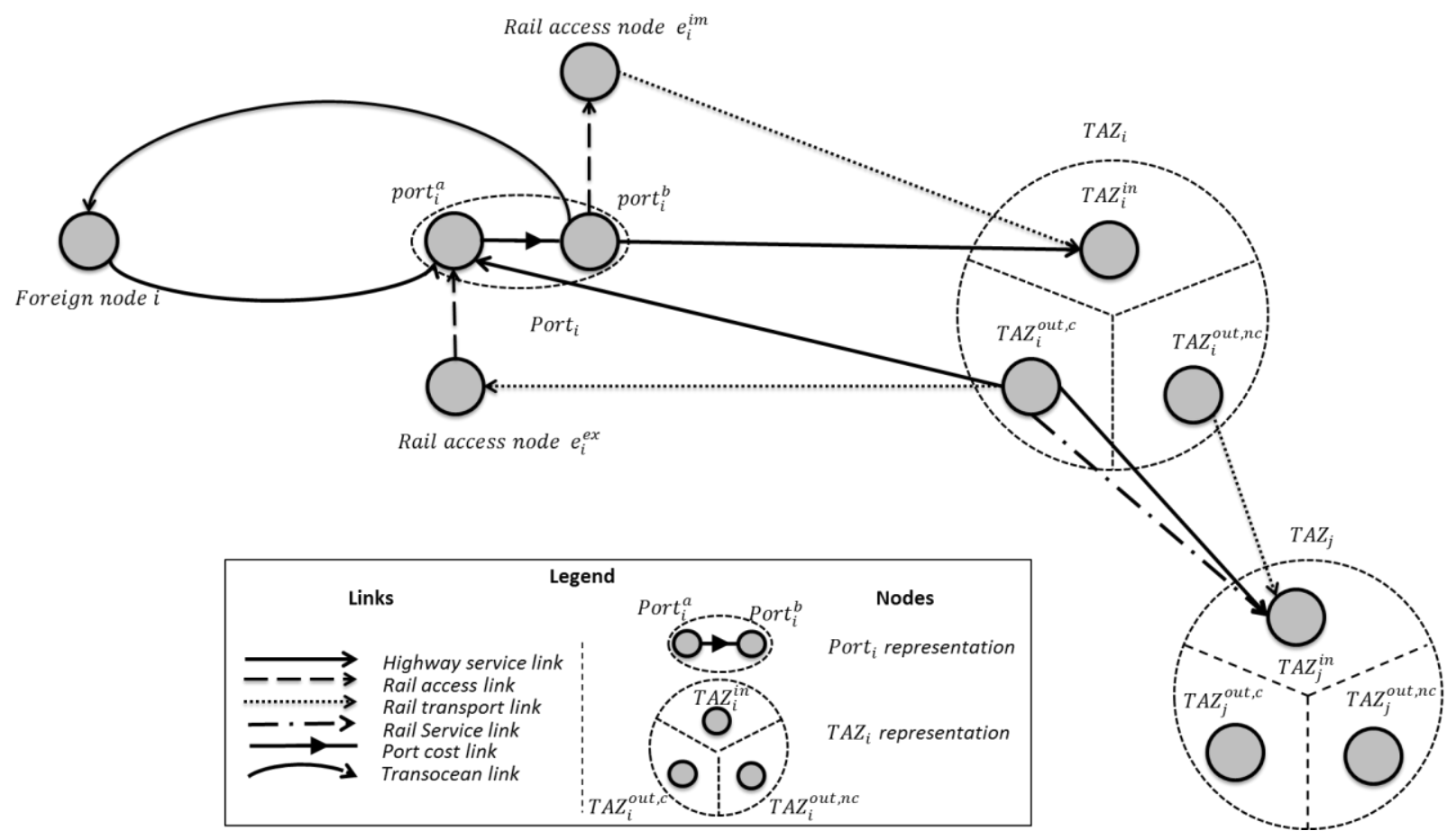

Fig. 3. Upper level network

It is important to notice three characteristics of the network described in Fig. 3. First, a port is represented using two nodes and a directional link connecting them ( $\operatorname{port}_{i}^{a}$ and port $t_{i}^{b}$. This is done to aggregate imports and exports, to compute the port generalized cost, as well as enforce capacity constraints.

Second, for domestic containerized traffic between $T A Z_{i}$ and $T A Z_{j}$, the cost of using rail is captured in the rail service link, as shown in Fig. 3. The rail service link is essentially the combination of rail access link and rail transport link. The rail transport link represents the cost of using rail, calculated from the lower level.

Third, and as illustrated in Fig. 3, the $T A Z_{i}$ node is split into three separate nodes. The node $T A Z_{i}^{\text {in }}$ is the sink for all traffic bound for $T A Z_{i}$. The other two nodes, $T A Z_{i}^{\text {out,c }}$ and 
$T A Z_{i}^{\text {out }, n c}$ are the origin nodes for shipments that originate at $T A Z_{i}$. Two nodes are necessary for for two reasons. First, so that the route choice can be tailored to each type of shipment (containerized and non-containerized). Second, in the lower-level rail yards are explicitly included and only non-containerized shipments use these yards. By mainitaining two separate nodes of origin by TAZ, containerized and noncontanierzed flows can be treated seperately.

The cost function is given in Eq.(8) for each non-rail associated link, $a$, in the network.

$$
C_{a}\left(v_{a}\right)=c_{a}^{0}\left(1+\alpha_{a}\left(\frac{v_{a}}{U_{a}}\right)^{\beta_{a}}\right)
$$

where $v_{a}$ and $U_{a}$ are, respectively, the traffic volume and the capacity of link $a, c_{a}^{0}$ is the cost of using link $a$ when the volume is zero, and $\alpha_{a}$ and $\beta_{a}$ are link specific parameters. We assume that $\alpha_{a}=0$ for transocean links and highway service links, which means the cost is independent of volume for movements along the links that connect foreign and U.S. ports, or on links that represent the U.S. highway system.

The cost functions for rail service links for domestic traffic, to support the allocation of containerized traffic to the rail network when both the origin and destination are in the U.S is given in Eq.(9). We assume that the probability that goods are transported either by rail or truck at each O-D pair in the U.S. follows a logit distribution. Suppose that $q_{m n}$ is the volume to be transported from origin $m$ to destination $n$. The cost of use a rail service link $a$, to transport volume $v_{a}$ for the O-D pair $m n$, takes the following form.

$$
C_{a}\left(v_{a}\right)=C_{m n}^{r}+\frac{1}{\theta_{m n}} \ln \left(\frac{v_{a}}{q_{m n}-v_{a}}\right)-\varphi_{m n}
$$


where $C_{m n}^{r}$ is the cost to transport the volume from the origin to the destination by rail calculated from the lower level model; $\theta_{m n}$ is the unit conversion parameter; and $\varphi_{m n}$ is the rail bias parameter at origin $m$ and destination $n . \theta_{m n}$ and $\varphi_{m n}$ must be estimated from available data.

The cost functions for rail access links at ports are defined as follows. Suppose that $U_{i}^{i m}$ is the capacity of port $i$ to transfer imported containers to the rail network. The cost to use the rail access link $a$ is assumed to take the following form.

$$
C_{a}\left(v_{a}\right)=\frac{1}{\theta_{i}} \ln \left(\frac{v_{a}}{U_{i}^{i m}-v_{a}}\right)-\varphi_{i}^{i m} .
$$

Similarly, suppose that $U_{i}^{e x}$ is the capacity of port $i$ to transfer containers from the rail network to export.

$$
C_{a}\left(v_{a}\right)=\frac{1}{\theta_{i}} \ln \left(\frac{v_{a}}{U_{i}^{e x}-v_{a}}\right)-\varphi_{i}^{e x}
$$

where $\theta_{i}$ is the unit conversion parameter and $\varphi_{i}^{i m}, \varphi_{i}^{e x}$ are the rail bias parameters at the port. As in Jones et al (2011), we use the capacities in Eq.(10) and Eq.(11) to calibrate the mode split between rail and truck at the ports for imports and exports separately.

For non-containerized traffic, nearly all coal and over $68 \%$ of grain are transported by rail in highly productive unit trains, which typically operate continuously and generally follow "direct shipping routes" (Association of American Railroads, 2017). Thus, for these two commodities, as well as for containerized traffic, we assume they bypass rail yards.

The cost to use the rail transport link $a$ to transport a volume $v_{a}$ from origin $m$ to destination 
$n$ takes the following form.

$$
C_{a}\left(v_{a}\right)=C_{m n}^{r}
$$

where $C_{m n}^{r}$ is the cost to transport the volume from the origin to the destination by rail calculated from the lower level model.

The cost function for each port in the U.S. as given in Eq.(13). We assume the unit cost function for port $i$ takes the form:

$$
C_{a}\left(v_{a}\right)=c_{i}+\beta d_{i}\left(v_{a}\right)
$$

where $c_{i}$ is the constant unit handling cost in the port; $v_{a}$ is the total volume through the port $i$; $d_{i}$ is the delay at the port, which is a function of the volume; and $\beta$ is the unit conversion parameter that translates time delays into equivalent cost (Jones et al, 2011).

\subsection{Lower Level Rail Traffic Assignment Optimization Problem}

As mentioned previously, we assume that the rail network is operated via a system optimal paradigm. It is this assumption that leads to the use of a bi-level model structure. The remainder of this subsection gives the model formulation for the rail network.

We assume that the cost function for these links takes the following form (Clarke, 1995).

$$
C_{a}\left(v_{a}\right)=c_{a}^{0}\left(1+\gamma_{a} v_{a}+\alpha_{a}\left(\frac{v_{a}}{U_{a}}\right)^{\beta_{a}}\right)
$$

where $v_{a}$ and $U_{a}$ are respectively the traffic volume and the capacity of the link; $c_{a}^{0}$ is the cost for using the link when the volume is zero on the link; and $\alpha_{a}, \beta_{a}$ and $\gamma_{a}$ are the parameters associated with the link. 
For a given shipment from origin $s$ to destination $t$, we let $q_{s t}$ be the volume needed to be transported, and $K_{s t}$ be the set of the rail paths that connect the origin and the destination. It might be useful to note that each origin $s$ is defined as either containerized or non-containerized; therefore knowing the origin implies the type of goods to be moved. Also, recall that the paradigm in the rail network is to assign the traffic based on the system optimal principle, i.e., assign the traffic volume to the paths $f_{s t}^{k}$, for $k \in K_{s t}$. Minimizes

$$
\sum_{a} C_{a}\left(v_{a}\right) v_{a}
$$

Subject to

$$
\begin{gathered}
\sum_{k \in K_{s t}} f_{s t}^{k}=q_{s t} \quad \forall s, t \\
v_{a}=\sum_{s, t} \sum_{k \in s t} \delta_{s t}^{a k} f_{s t}^{k} \quad \forall a \\
f_{s t}^{k} \geq 0 \quad \forall s, t, k
\end{gathered}
$$

We employ Frank-Wolfe (Sheffi, 1985) to solve this formulation, using marginal travel costs rather than the volume to delay curves directly. Also, we generate paths while solving the problem rather than pre-compute them. When implementing the algorithm, if the origin is for non-containerized traffic, bypass links are not included in the network when the shortest path is computed. 


\section{Chaper 4. Solution Procedure}

We propose a heuristic algorithm that iterates between the lower and upper level optimization problems to develop the flow assignment.

\subsection{Bi-level traffic assignment algorithm}

1. Lower level Initialization. Assuming all link volumes are zero on all rail links, find the path that minimizes the total cost for each port-destination, origin-port, containerized O-D and non-containerized O-D by rail in the U.S. The cost will be the coefficient, $C^{r}$, for the rail links in Eq.(9) and Eq.(12). Let $l$ be the number of iterations completed and $L$ be the maximum number of iterations. Let $l=1$.

2. Solve the upper level model. Given the cost coefficient $C^{r}$, identified from either step 1 if $l=1 \quad$ or step 4 if $l>1$, solve the optimization problem given in Eqs. (1) $-(5)$ to create the user equilibrium assignment for the upper level service network and to identify the O-D table for the lower level model. We solve this model by using the Frank-Wolfe algorithm (Sheffi, 1985) but convert the sub-problem in each step into a multi-commodity network flow problem with capacity constraints.

3. Test. If $l>1$ and $l \leq L$ stop if the difference in link flows from iteration $l$ and $l-1$ are sufficiently close. Otherwise, $l=l+1$ and go to step 4 .

4. Solve the rail optimization model. This step consists of the following two steps:

4.1 Solve the model given in Eqs. (15) - (18) using the O-D table developed in Step 2. Again, we use the Frank-Wolfe algorithm with marginal costs to identify a system optimal solution. 
4.2. Based on the solution from step 4.1, update $C^{r}$. Following section describes how we estimate for $C^{r}$. Go to step 2 .

\subsection{Computing $C^{r}$ (expected rail costs by $O-D$ pair)}

As mentioned previously, flows in the lower level rail network give system optimal link volumes. However, the upper level requires a travel cost on each rail link (each represents rail travel for a unique O-D pair). In order to compute this, in the lower level model, at each iteration of the Frank-Wolfe algorithm for each O-D pair, the volume on each path identified is updated. It is worth remembering that marginal cost is used to optimize the link flows in the lower level but the rail travel cost communicated to the upper level is the actual cost. More specifically, the procedure used to estimate these rail travel costs is as follows.

1. Perform all-or-nothing assignment based on $C_{a}=C_{a}(0)$. Record the path volume and the links in the path for each O-D pair $f_{s t}^{0}$ identified in the assignment. This yields $\left\{v_{a}^{1}\right\}$. Set counter $\mathrm{k}=1$.

2. Update link cost. Set $C_{a}^{k}=C_{a}\left(v_{a}^{k}\right)$.

3. Perform all-or-nothing assignment based on updated cost. Find the shortest path $f_{s t}^{k}$ for each O-D pair and corresponding link volumes $\left\{w_{a}^{k}\right\}$

4. Line search. Find $\lambda_{k}$ that solves

$$
\operatorname{Min} \sum_{a} \int_{0}^{v_{a}^{k}+\lambda_{k}\left(w_{a}^{k}-v_{a}^{k}\right)} C_{a}(\omega) d \omega, 0 \leq \lambda_{k} \leqq 1 .
$$

5. Volume shift. Set $v_{a}^{k+1}=v_{a}^{k}+\lambda_{k}\left(w_{a}^{k}-v_{a}^{k}\right)$. Set $f_{s t}^{k}=\lambda_{k} q_{s t}$. Set all previous paths volumes to $\left(1-\lambda_{k}\right) f_{s t}^{i}, 0 \leq i \leq k-1$ 
6. Convergence test. If the difference in link flows from lower level iteration $k$ and $k-1$ are sufficiently close, $\left\{v_{a}^{k}\right\}$ is the set of link flows. Compute the actual travel cost for all links and the corresponding travel cost for all $k$ paths. The expected travel cost for each O-D pair for upper level iteration $l$ equals: $C_{s t}^{r l}=\frac{\sum_{k \in K_{s t}} f_{s t}^{k}{ }^{*} C_{s t}^{k}}{q_{s t}}$, where $C_{s t}^{k}$ is the travel cost of using path $k . K_{s t}$ is the set of the used paths. If the criterion is not met, set $k=k+1$, go to step 2.

Now we update the $C_{s t}^{r}$ for Eq.(9) and Eq.(12) for the next upper level calculation as follows:

$$
C_{s t}^{r}=\frac{C_{s t}^{r l}+l * C_{s t}^{r \prime}}{l+1}
$$

Where the calculation of the expected travel cost $C_{s t}^{r}$ is smoothed with those computations, $C_{s t}^{r \prime}$, from the previous iterations. 


\section{Chaper 5. Model calibration}

Model calibration is required to identify values for the port capacities, rail capacities for facilities supporting each port, the per TEU port costs and the rail bias parameter so that the link volumes, port volumes and travel delays produced by the model match empirical observations of these values. Further, it is also important to compare the link volumes produced by the lower level rail model to link volumes reported by the Association of American Railroads (AAR) (Cambridge Systematics Inc., 2007). Next Section describes the upper level model calibration and then we examine the link volumes in the rail model.

\subsection{Upper level calibration}

The upper level model has 46 countries (reflected as foreign ports that are assumed to be the international origins and destinations), 27 U.S. ports and 84 domestic TAZs. The 46 countries represent over 94\% (PIERS, 2006) of total containerized trade with the U.S. through these 27 ports. Furthermore, the 27 ports represent over 87\% (American Association of Port Authorities, 2010) of total containerized traffic of U.S. ports.

We set $\theta_{i}$ equal to 0.013 as in Jones et al (2011) for all ports. Using a single value for all ports has the advantage of implying that the sensitivity of mode choice decisions to changes in rail or truck costs is the same at all ports. $\varphi_{i}^{i m}$ and $\varphi_{i}^{e x}$ plays a role of capturing the impact of other factors that differ by port, such as the rail access availability. Table. 2 gives the remainder of the parameter values required. Note that we assume the same port rail capacities for exports via a port as for imports. Finally, it is important to notice that, based on the choice model adopted, the impact of the per unit cost at a port is only relavent in comparision to the costs at other ports and 
hence the actual magnitide is not intriscially meaningfull.

Table. 2. Estimated parameters of port capacity, port handling cost, rail capacity and rail bias parameter.

\begin{tabular}{|c|c|c|c|c|}
\hline \multirow[t]{2}{*}{ Port } & Port capacity $\left(U_{i}\right)$ & $c_{i}$ & $\begin{array}{l}\text { Port rail capacity } \\
\quad\left(U_{i}^{i m}, U_{i}^{e x}\right)\end{array}$ & $\varphi_{i}^{i m}, \varphi_{i}^{e x}$ \\
\hline & TEU/week & $\$ / T E U$ & TEU/week & $\$ /$ TEU \\
\hline Baltimore & 28,800 & 515 & 20,000 & 465 \\
\hline Boston & 8,000 & 720 & 2,400 & 300 \\
\hline Charleston & 82,900 & 30 & 22,000 & 225 \\
\hline Chester PA & 6,500 & 550 & 1,300 & 400 \\
\hline Freeport TX & 2,200 & 315 & 500 & 300 \\
\hline Galveston & 700 & 525 & 200 & 200 \\
\hline Gulfport & 9,800 & 700 & 2,000 & 450 \\
\hline Houston & 35,400 & 235 & 20,000 & 635 \\
\hline Jacksonville & 53,300 & 100 & 3,000 & 250 \\
\hline Los Angeles-Long beach & 529,100 & 0 & 200,000 & -60 \\
\hline Miami & 43,000 & 230 & 14,200 & 425 \\
\hline Mobile & 7,000 & 435 & 1,100 & 300 \\
\hline New Orleans & 16,500 & 700 & 3,100 & 450 \\
\hline New york-New jersey & 143,400 & 460 & 60,000 & 600 \\
\hline Norfolk & 54,900 & 245 & 26,000 & 425 \\
\hline Oakland & 49,500 & 490 & 24,000 & 300 \\
\hline Philadelphia & 16,700 & 550 & 3,300 & 400 \\
\hline Portland OR & 10,200 & 590 & 2,000 & 300 \\
\hline Everglades & 39,000 & 215 & 9,400 & 350 \\
\hline Richmond VA & 1,200 & 455 & 800 & 400 \\
\hline San francisco & 1,000 & 625 & 400 & 200 \\
\hline Savannah & 102,800 & 0 & 22,000 & 175 \\
\hline Seattle-Tacoma & 160,300 & 265 & 80,000 & -110 \\
\hline Tampa & 1,400 & 320 & 400 & 150 \\
\hline Palm BCH & 7,600 & 210 & 1,200 & 350 \\
\hline Wilmington DE & 9,000 & 520 & 3,100 & 400 \\
\hline Wilmington NC & 11,800 & 260 & 2,400 & 200 \\
\hline
\end{tabular}

Fig. 4 illustrates the quality of the match between the weekly estimated TEUs by port (the values in Table. 2) and the data published by AAR (Cambridge Systematics Inc., 2007). The match at LA and LB, New York are very close with errors at each of about 3\%. The maximum error at the 
ports with more than 40,000 TEUs per week (LA and LB, New York and New Jersey, Seattle and Tacoma, Savannah, Oakland, Norfolk) is around 5\%.

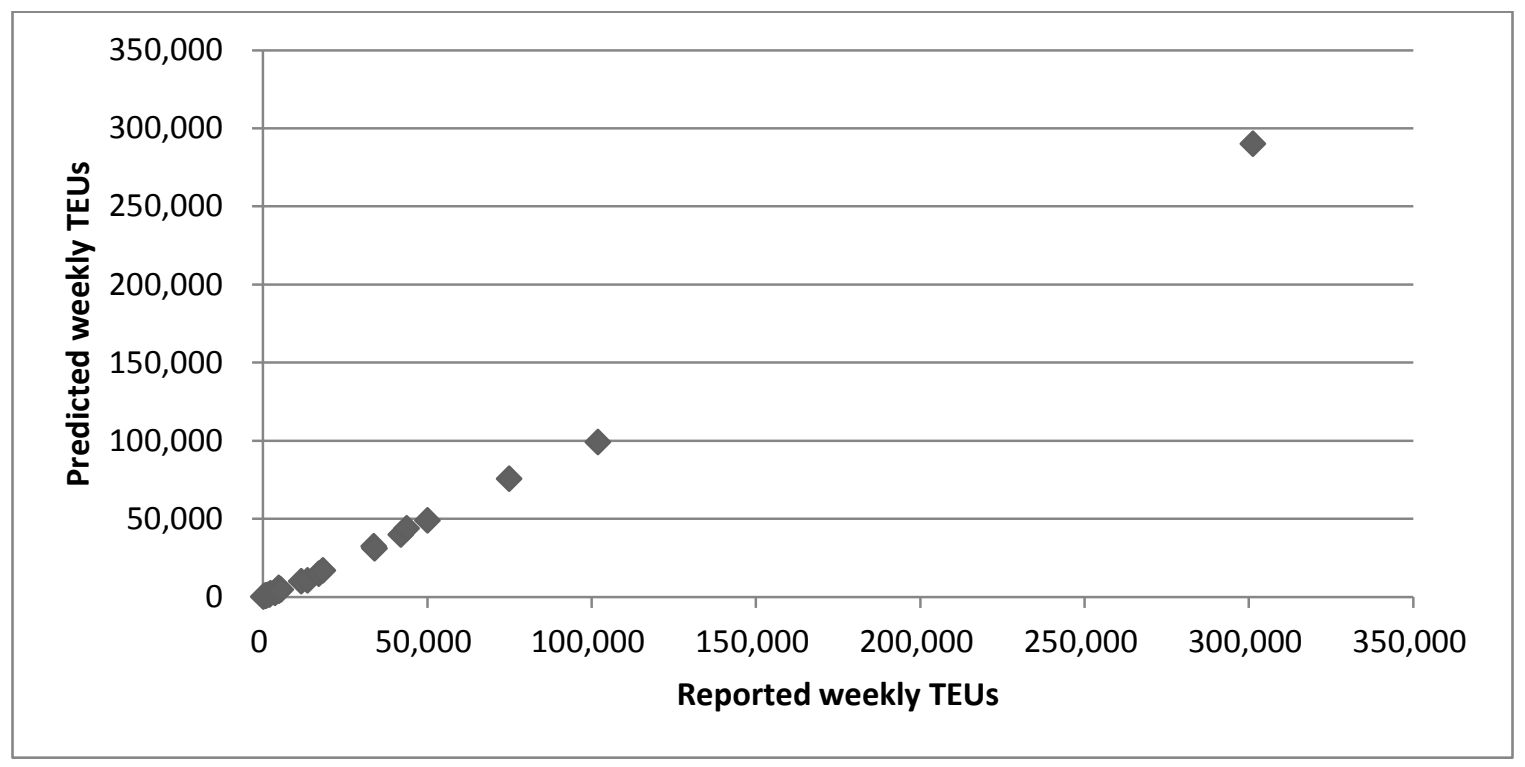

Fig. 4. Comparison of model-estimated port volumes and those reported for 2007 (AAPA, 2010).

Fig. 5 gives a comparison of the mode split of the domestic portion of the movement of U.S. imports and exports, predicted by the model for ports where at least 10,000 TEUs/week are handled, and independent estimates based on a variety of sources. The estimation of the mode share is accomplished by integrating data from multiple sources, such as The Geography of Transport Systems (2007). The data on rail and truck splits at the ports is very limited, partially due to the fact that trucks may shuttle containers to nearby rail loading points. These containers travel most of their inland distance by rail but appear to be leaving by truck. The largest discrepancy happens at the port of New York and New Jersey. The model predicts that $26 \%$ of the volume is shipped via rail, compared to the independent estimates of $15 \%$. The average absolute error is $4 \%$. 


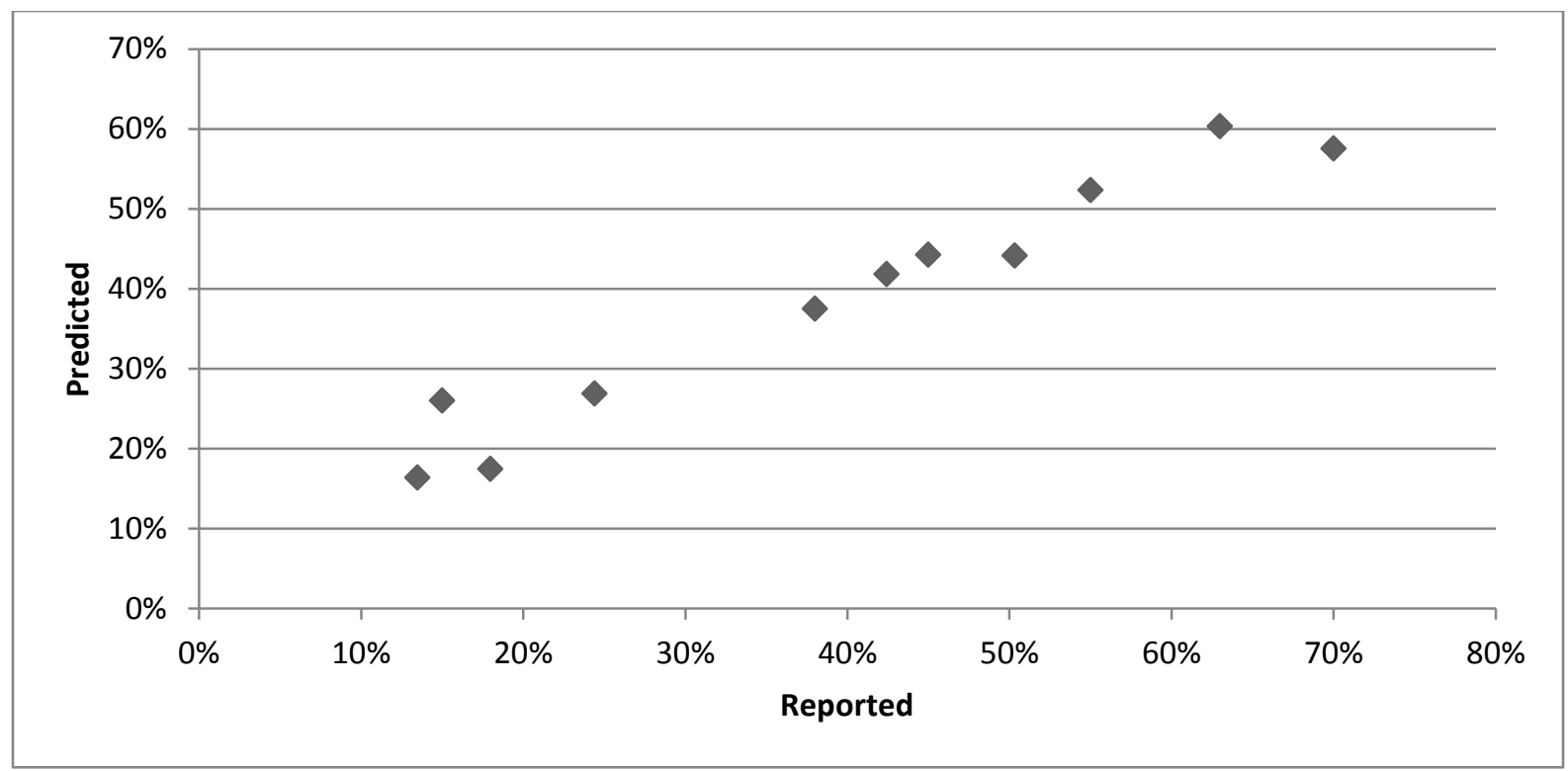

Fig. 5. Comparison of estimated and "reported" rail penetration by ports.

We set $\theta_{m n}$ to 0.013 for all O-D pairs. For the rail bias parameter, $\varphi_{m n}$, we chose to adopt values based on the distance between the origin $m$ and the destination $n$. For O-D pairs for which the distance is less than 750 miles, from 750 to 1,250 miles, and greater than 1,250 miles, $\varphi_{m n}$ are set equal to 100,0 , and -150 respectively. Using these values, Fig. 6 gives the resultant mode split as a function of distance, along with a comparison with data obtained from Cambridge Systematics, Inc. (Cambridge Systematics, 2007). Again, the match is quite close with larger discrepancies for domestic movements above 1,250 miles, which is about $17 \%$ of TEUs. 


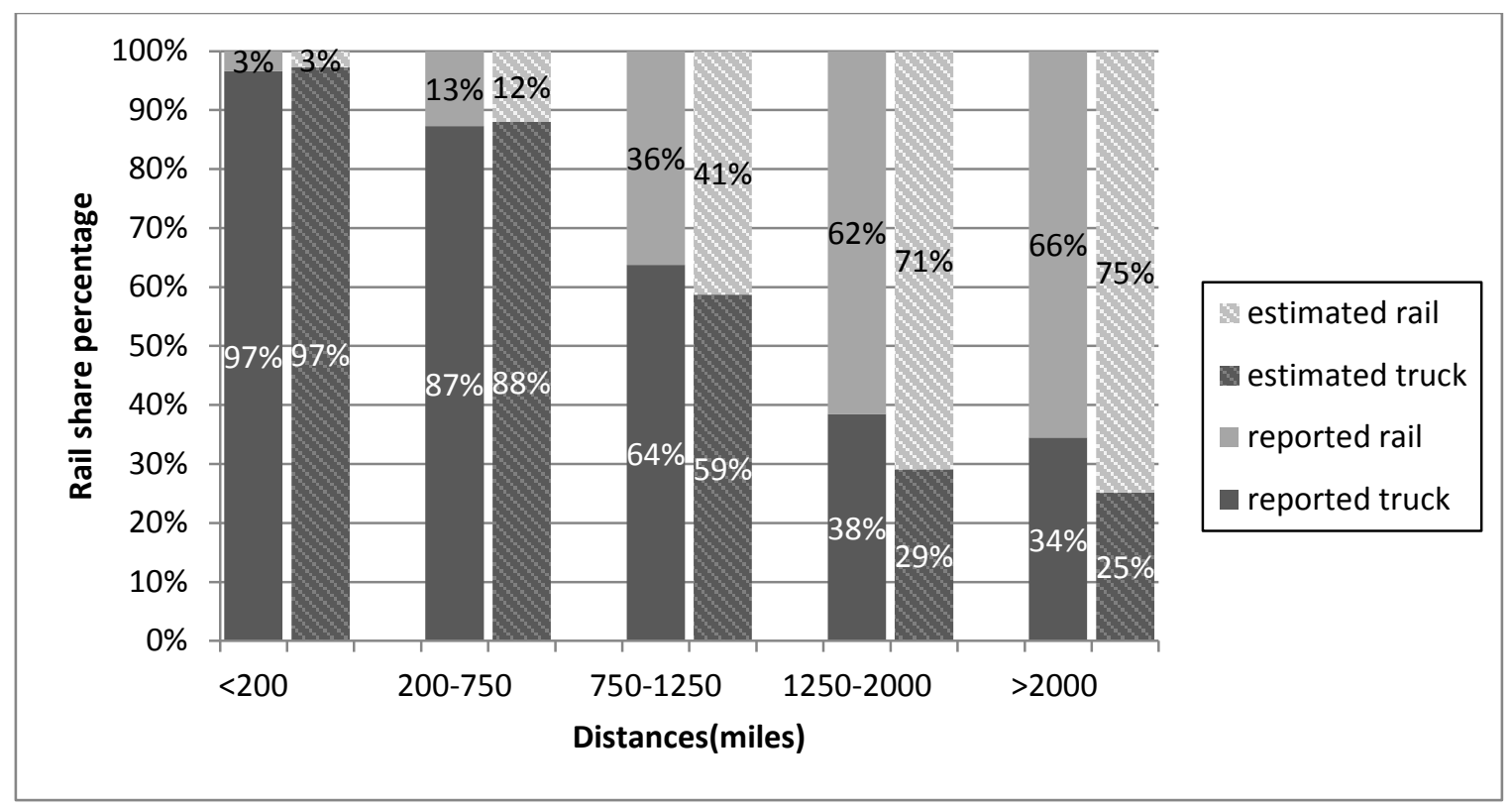

Fig. 6. Comparison of estimated and reported domestic container traffic mode split by

distance.

\subsection{Lower level illustration and calibration}

We represent the rail network using the GIS network developed by Oak Ridge National Laboratory (2005). That network has 10,145 links, 4,903 nodes and is illustrated in Fig. 7. Clarke (1995) identified 12 link types based on terrain condition, siding space, and single/double track. We focus on flat double track; flat single track, and both of them sidings less than 10 miles. In this case, $\gamma_{a}=0.001723, \alpha_{a}=29.52711, \beta_{a}=25.0, U_{a}=258$ trains $/$ day for double track, and $\gamma_{a}=0.005269, \alpha_{a}=29.52711, \beta_{a}=25.0, U_{a}=86$ trains/day for single track. These parameters are the coefficients in the link delay functions given in Eq. (14). 


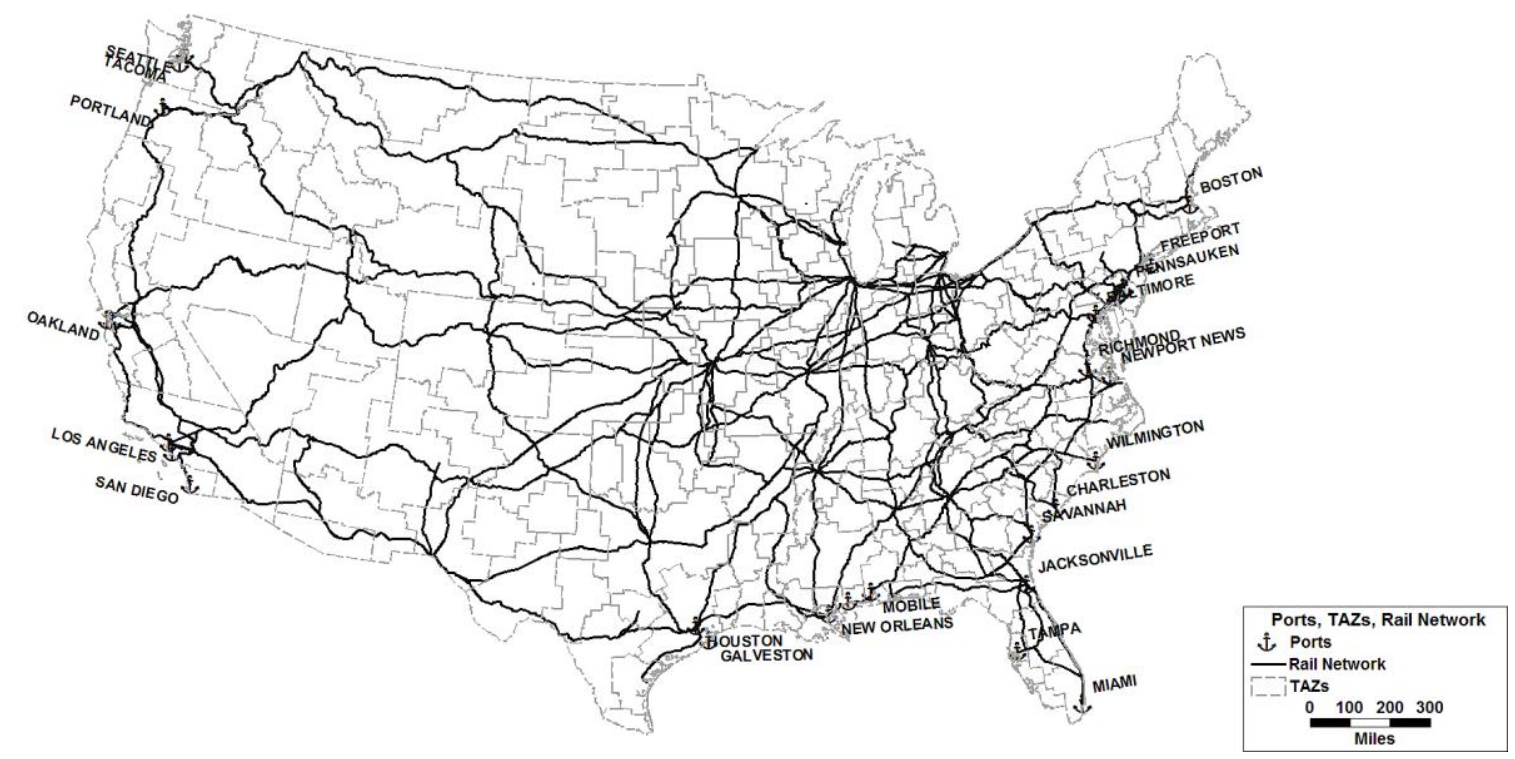

Fig. 7. Ports, TAZs and rail network (Oak Ridge National Laboratory, 2005).

The volume-to-capacity ratio, expressed as a level of service (LOS) estimated by the model, is similar to data published by AAR (Cambridge Systematics Inc., 2007). The reported and the estimated LOS are given in Table. 3. The largest discrepancy between the reported results and the model estimates lies in LOS B and C. However, both B and C are within the same group of "below capacity" which implies short delays. The overall fraction of tracks in categories A through $\mathrm{C}$ is $88 \%$ compared to the model estimate of $89 \%$. Fig. 8 shows the estimated link volumes by TEUs/week.

Table. 3. Description of LOS grade and comparison of reported and estimated LOS grade.

\begin{tabular}{|c|c|c|c|c|c|}
\hline LOS & $\begin{array}{l}\text { LOS in relative } \\
\text { to Capacity }\end{array}$ & Description & $\begin{array}{l}\text { Volume/ } \\
\text { Capacity } \\
\text { ratio }\end{array}$ & $\begin{array}{c}\text { Reported } \\
\text { mileage/total } \\
\text { mileage }\end{array}$ & $\begin{array}{c}\text { Estima } \\
\text { ted } \\
\text { mileag } \\
\text { e/total } \\
\text { mileag } \\
\text { e }\end{array}$ \\
\hline A & Below & Low to moderate train flows with & 0.0 to 0.2 & $19.0 \%$ & $20.3 \%$ \\
\hline B & capacity & capacity to accommodate & 0.2 to 0.4 & $30.0 \%$ & $37.7 \%$ \\
\hline C & & $\begin{array}{l}\text { maintenance and recover from } \\
\text { incidents }\end{array}$ & 0.4 to 0.7 & $39.0 \%$ & $31.3 \%$ \\
\hline D & Near capacity & $\begin{array}{l}\text { Heavy train flow with moderate } \\
\text { capacity to accommodate }\end{array}$ & 0.7 to 0.8 & $9.0 \%$ & $10.3 \%$ \\
\hline
\end{tabular}




\begin{tabular}{cccccc}
\hline \multicolumn{5}{c}{$\begin{array}{c}\text { maintenance and recover from } \\
\text { incidents }\end{array}$} \\
\hline E & At capacity & $\begin{array}{c}\text { Very heavy train flow with very } \\
\text { limited capacity to accommodate } \\
\text { maintenance and recover from } \\
\text { incidents }\end{array}$ & 0.8 to 1.0 & $3.0 \%$ & $0.4 \%$ \\
\hline $\mathrm{F}$ & $\begin{array}{c}\text { Above } \\
\text { capacity }\end{array}$ & $\begin{array}{c}\text { Unstable flows; service breakdown } \\
\text { conditions }\end{array}$ & $>1.0$ & $<1.0 \%$ & $0.0 \%$ \\
\hline
\end{tabular}

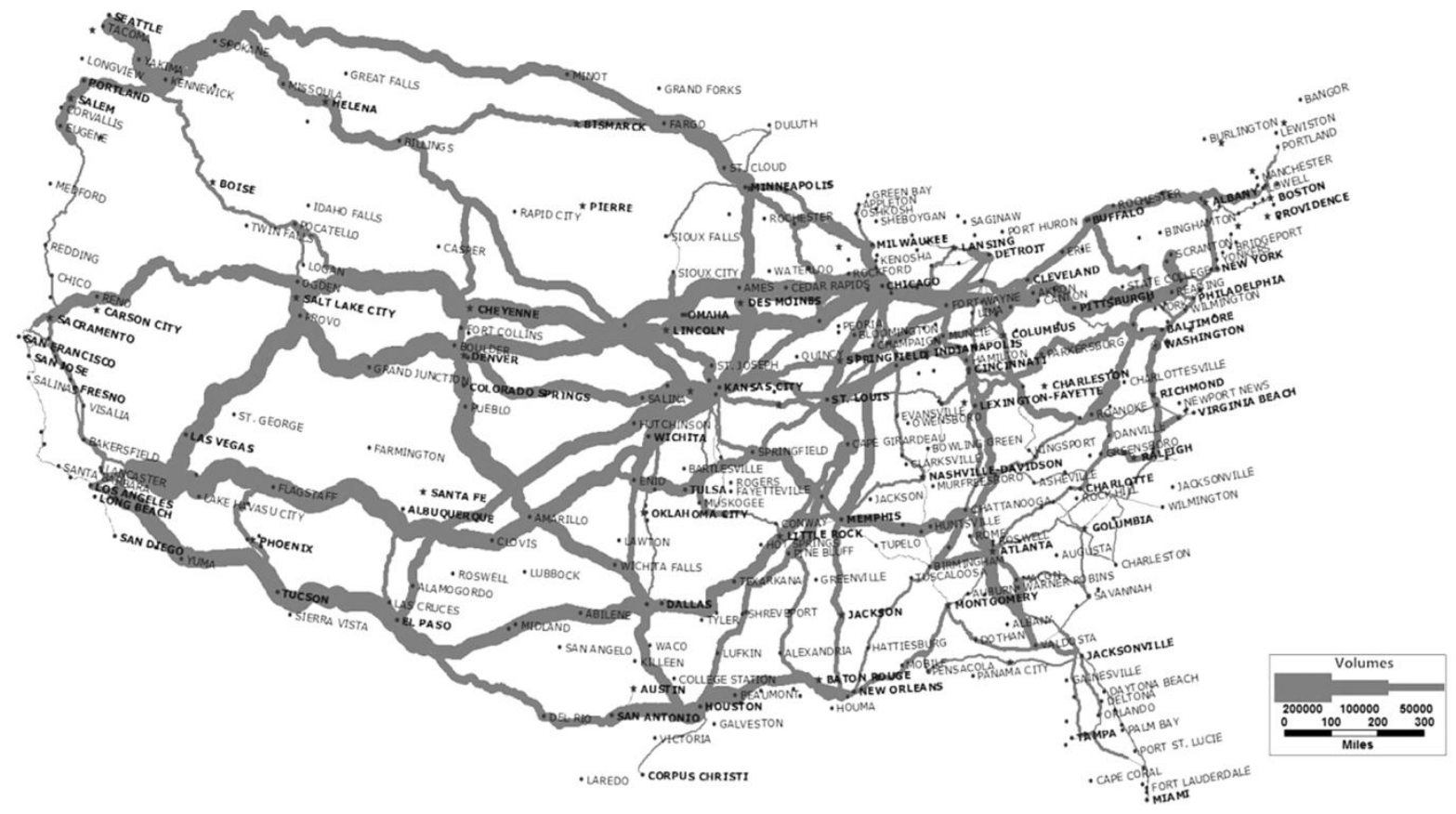

Fig. 8. Rail network link volumes under SO. 


\section{Chaper 6. Comparison of SO and UE link assignment in the rail network}

We assume that the rail system is operated according to the principle of system optimal (SO). However, it is interesting to understand how the costs of this system would vary if the principle were user equilibrium (UE). Fig. 9 gives the cumulative costs for all rail traffic per week. It is important to notice that when the rail system is operated according to $\mathrm{SO}$, more carloads are handled and less cost is incurred then when it is operated as UE.

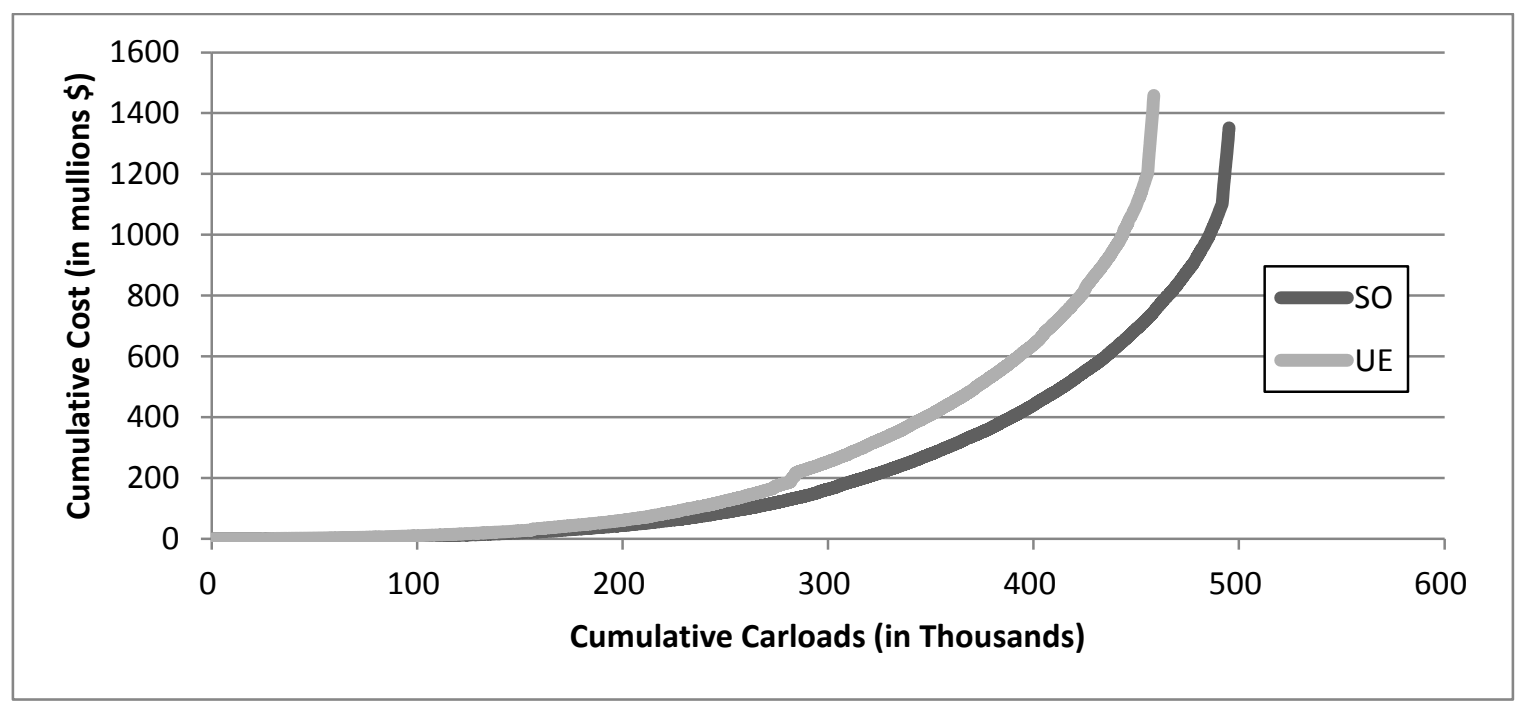

Fig. 9. Cumulative volumes and costs on the rail network.

Fig. 10 illustrates how the cumulative total costs from ultimate origin to ultimate destination vary based on whether SO or UE is adopted for the rail network. Notice that the cumulative costs are about 3.7\% lower when SO is used. Of course, not all O-D pairs benefit evenly from this. Fig. 11 gives a comparison of cost differences by OD pair between SO and UE basis. Among the around 6,000 total O-D pairs, 1,700 have similar O-D costs under both assumptions, 1,200 experience an increase in cost under the SO assumption, and 3,100 experience a decline in cost under the SO assumption. 


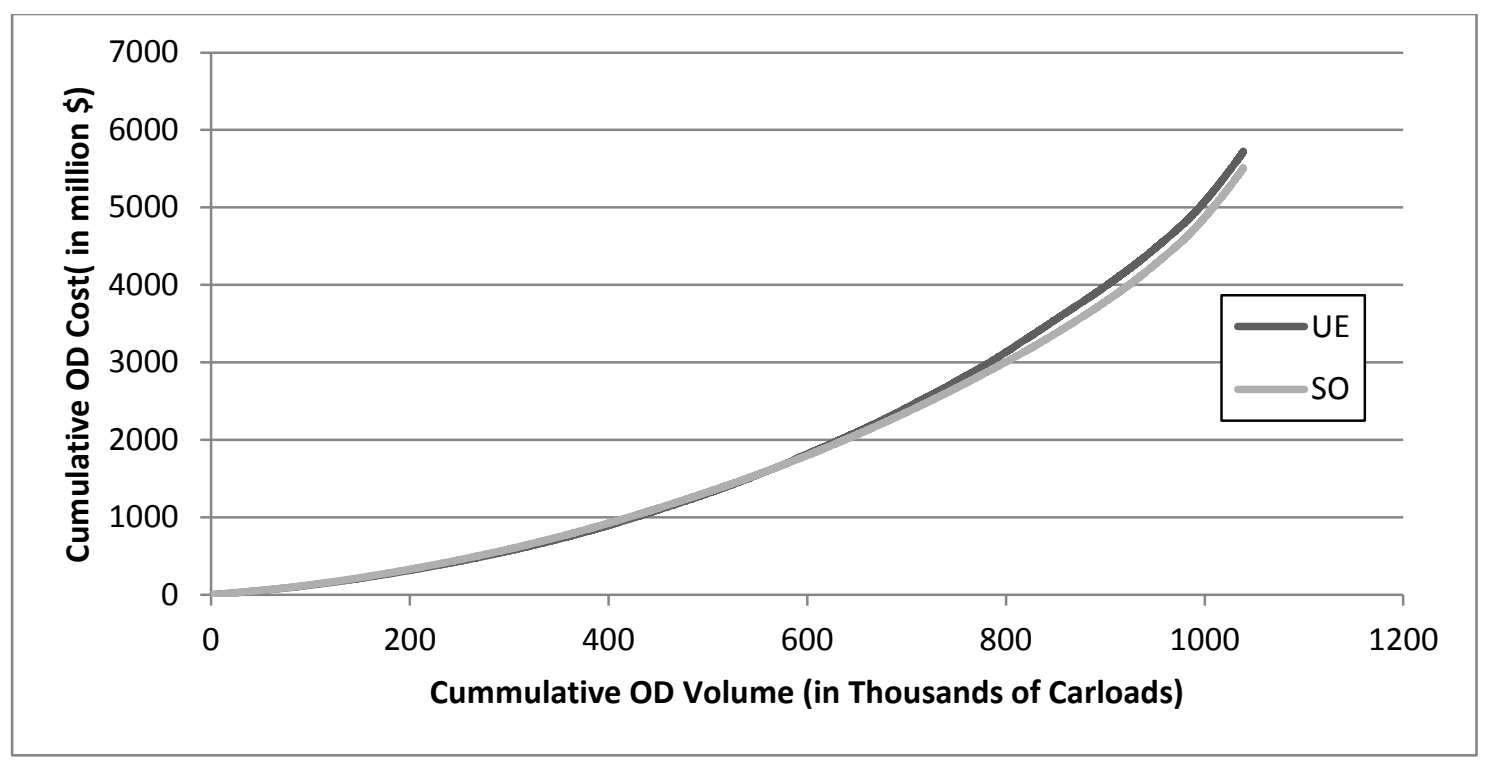

Fig. 10. Cumulative O-D volumes and costs.

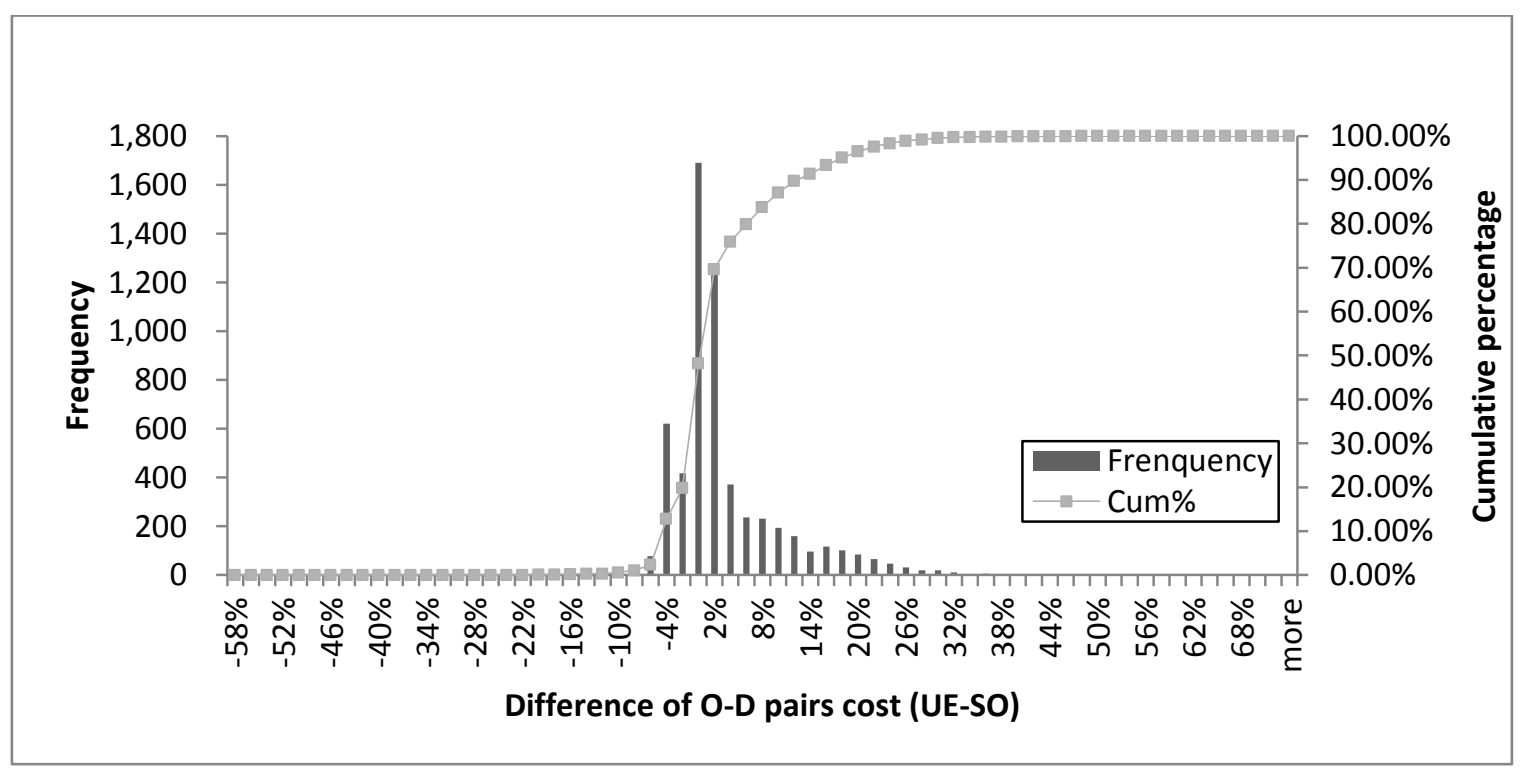

Fig. 11. Difference of costs by O-D pairs (SO and UE).

Table. 4 compares the percentage of track in each LOS category under both assumptions (SO and UE). We include the reports percentages in Table. 4 that are also given in Table. 3 for ease comparison. Both assumptions produce similar results. However, one might argue that the SO assumption is somewhat closer with about $11 \%$ of track in LOS E and F in comparison to about $8.3 \%$ for UE when the reported value is on the order of $12 \%$. 
Table. 4. Comparison of estimated LOS grade between SO and UE.

\begin{tabular}{|c|c|c|c|c|c|c|c|}
\hline LOS & Description & $\begin{array}{c}\text { Volume/ } \\
\text { Capacity } \\
\text { ratio }\end{array}$ & $\begin{array}{c}\text { Reported } \\
\text { mileage/tota } \\
\text { I mileage }\end{array}$ & $\begin{array}{c}\text { Estimated } \\
\text { mileage/total } \\
\text { mileage(SO) }\end{array}$ & $\begin{array}{c}\text { Estimated } \\
\text { mileage/total } \\
\text { mileage(UE) }\end{array}$ & $\begin{array}{l}\text { Closure of } \\
\text { LA and } \\
\text { LB(SO) }\end{array}$ & $\begin{array}{c}\text { Pricing } \\
\text { changes } \\
\text { in } \\
\text { California } \\
\text { ports(SO) }\end{array}$ \\
\hline A & & 0.0 to 0.2 & $19.0 \%$ & $20.1 \%$ & $21.6 \%$ & $20.2 \%$ & $20.8 \%$ \\
\hline B & Below capacity & 0.2 to 0.4 & $30.0 \%$ & $37.8 \%$ & $40.0 \%$ & $39.8 \%$ & $37.9 \%$ \\
\hline C & & 0.4 to 0.7 & $39.0 \%$ & $31.4 \%$ & $30.1 \%$ & $33.6 \%$ & $31.8 \%$ \\
\hline D & Near capacity & 0.7 to 0.8 & $9.0 \%$ & $10.1 \%$ & $3.4 \%$ & $6.1 \%$ & $9.1 \%$ \\
\hline $\mathrm{E}$ & At capacity & 0.8 to 1.0 & $3.0 \%$ & $0.6 \%$ & $4.9 \%$ & $0.4 \%$ & $0.4 \%$ \\
\hline $\mathrm{F}$ & Above capacity & $>1.0$ & $<1.0 \%$ & $0.0 \%$ & $0.0 \%$ & $0.0 \%$ & $0.0 \%$ \\
\hline
\end{tabular}




\section{Chaper 7. Capability of the model and its applications}

To illustrate the analyses that can be performed with the model we concentrate on two case studies: (1) a serious disruption that leads to the closure of the Ports of Los Angeles and Long Beach, and (2) imposition of user fees at all California ports.

\subsection{Example 1: Closure of the Ports at Los Angeles and Long Beach}

The postulated disruption is a complete inability to handle traffic at LA and LB. To perform this analysis, we assume that the O-D table remains the same and we center on the following three questions. First, is the current freight transportation system robust enough to adapt to this loss? More specifically, do other ports have enough capacity to accommodate the additional traffic from the ports of LA and LB? Second, if not, how much traffic cannot be accommodated? And third, for the traffic that can be accommodated, what are the costs of doing so?

The ports of LA and LB are the largest ports in the U.S. and together handled around $40 \%$ of the total U.S. imports and exports in 2007 (still true in 2015; Wang et al, 2016). Using the model, and prior to disruption, the ports of LA and LB handle about 290,000 TEUs/week; about 168,000 TEUs that are imports and 121,000 TEUs that are exports. Most of the traffic at these ports are from Asia, with about 103,000, 17,329 and 14,148 TEUs/week imported from Mainland China, Hong Kong, and Japan, respectively. These three origins comprise about $79 \%$ of total imports at LA and LB.

Fig. 12 shows the resulting volumes at the ports, when the ports of LA and LB are not available. Fig. 12 also gives the estimated capacities at each of the ports that are also included in Table. 2 to aid the reader. Of the ports with estimated capacities above 20,000 TEUs/week, the ports at 
Houston, Norfolk, Oakland, and Seattle and Tacoma are also very close to or at capacity post disruption. About $30 \%$ of the flows $(85,000$ TEUs/week) that originally used the ports at LA and LB were diverted to the ports of Seattle and Tacoma, leading to an increase in traffic of $112 \%$, thereby reaching the estimated physical capacity of these two ports. The volumes through the ports of Savannah and Charleston increased by 37,500 and 27,000 TEUs/week, respectively. The utilization of those ports post disruption is about $85 \%$ at Savannah and $72 \%$ at Charleston.

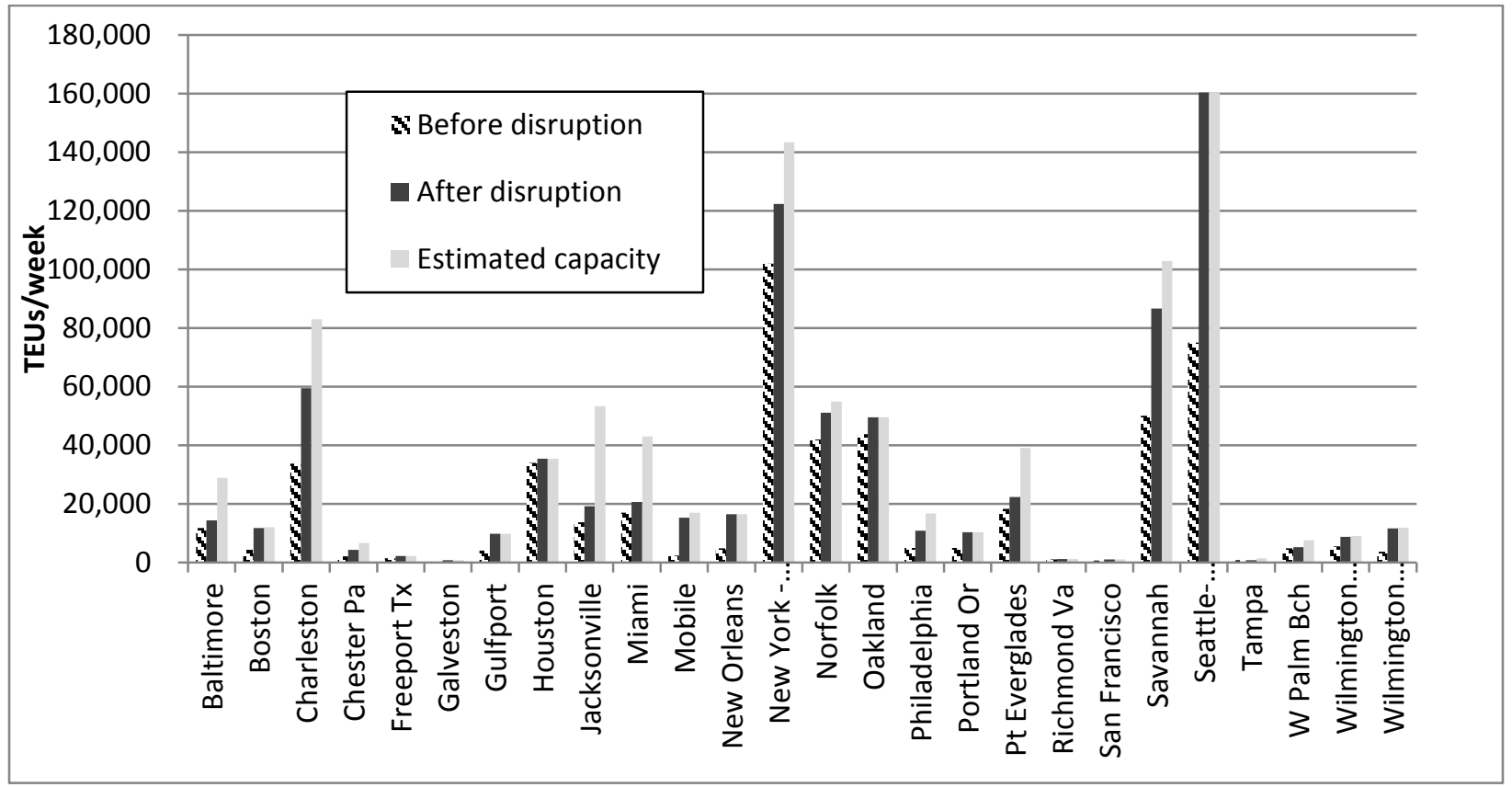

Fig. 12. Redistribution of port flows after disruption.

Fig. 13 gives the spatial distribution of the destination of U.S. imports that are handled by LA and LB, NY and NJ, Savannah, Seattle and Tacoma. It is useful to note that LA and LB serve a wide range of destinations, whereas the spatial distribution of the destinations served by Savannah are more clustered in the southeast. 


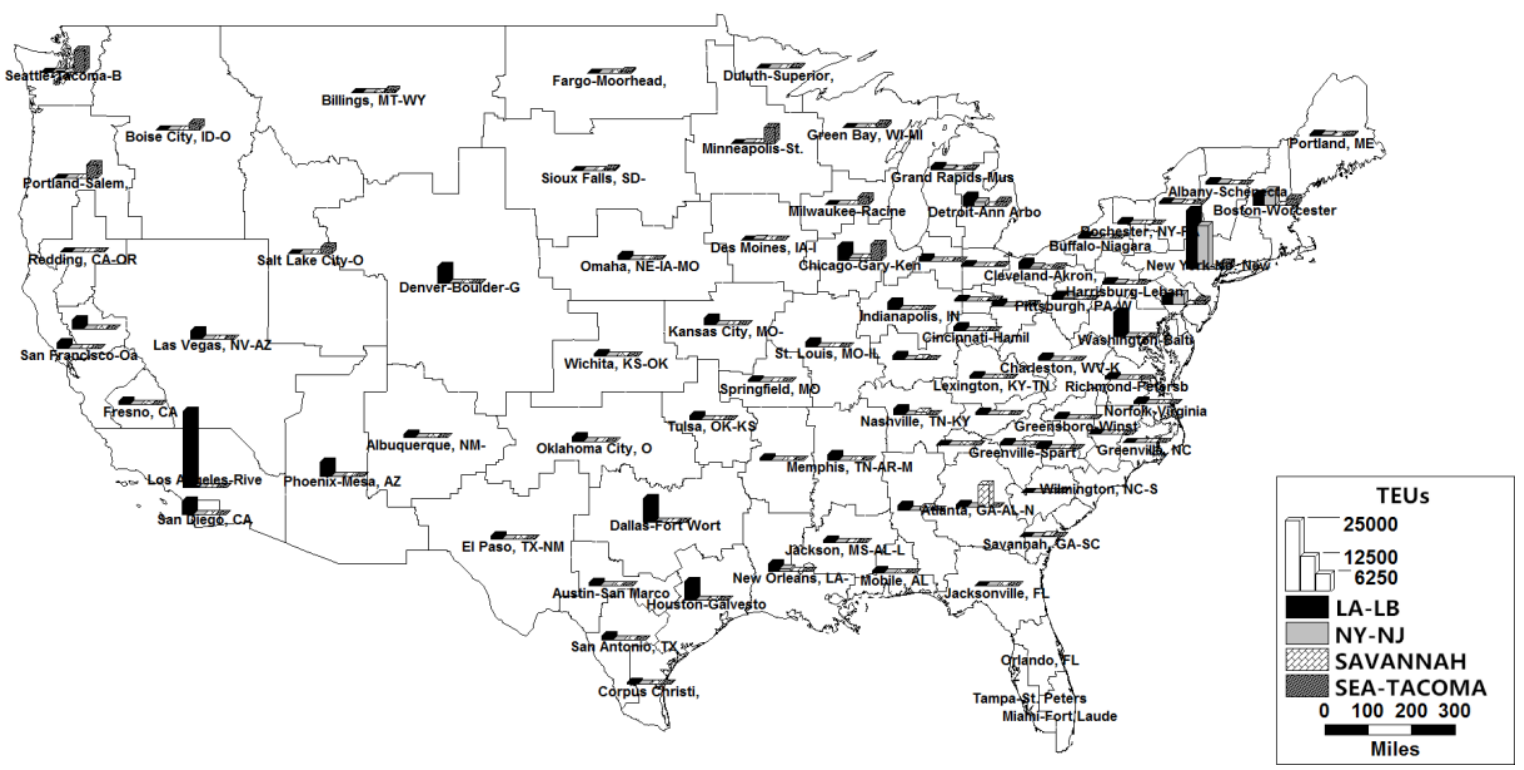

Fig. 13. Pre-disruption imports from selected major ports to TAZs.

The increased flows at Seattle and Tacoma mainly originated from, or are destined to, Southern California, or the Southwest/Mountain areas (i.e. Los Angeles, Denver, Phoenix and San Diego), as shown in Fig. 14. The ports of New York and New Jersey experiences volume increases of approximately 23,000 TEUs/week. Most of those flows originate from, or are destined to, New York and Chicago. Those flows were originally carried by rail from and to LA and LB, but as a result of the disruption, they divert to east coast ports as an alternative.

The disruption also results in a change in shipping costs and inventory costs. Prior to disruption, the total cost for the transport of all imports and exports is approximately $\$ 2.03$ billion/week. With the loss of LA and LB, the total cost rise to $\$ 2.26$ billion/week; about an $11 \%$ increase. 


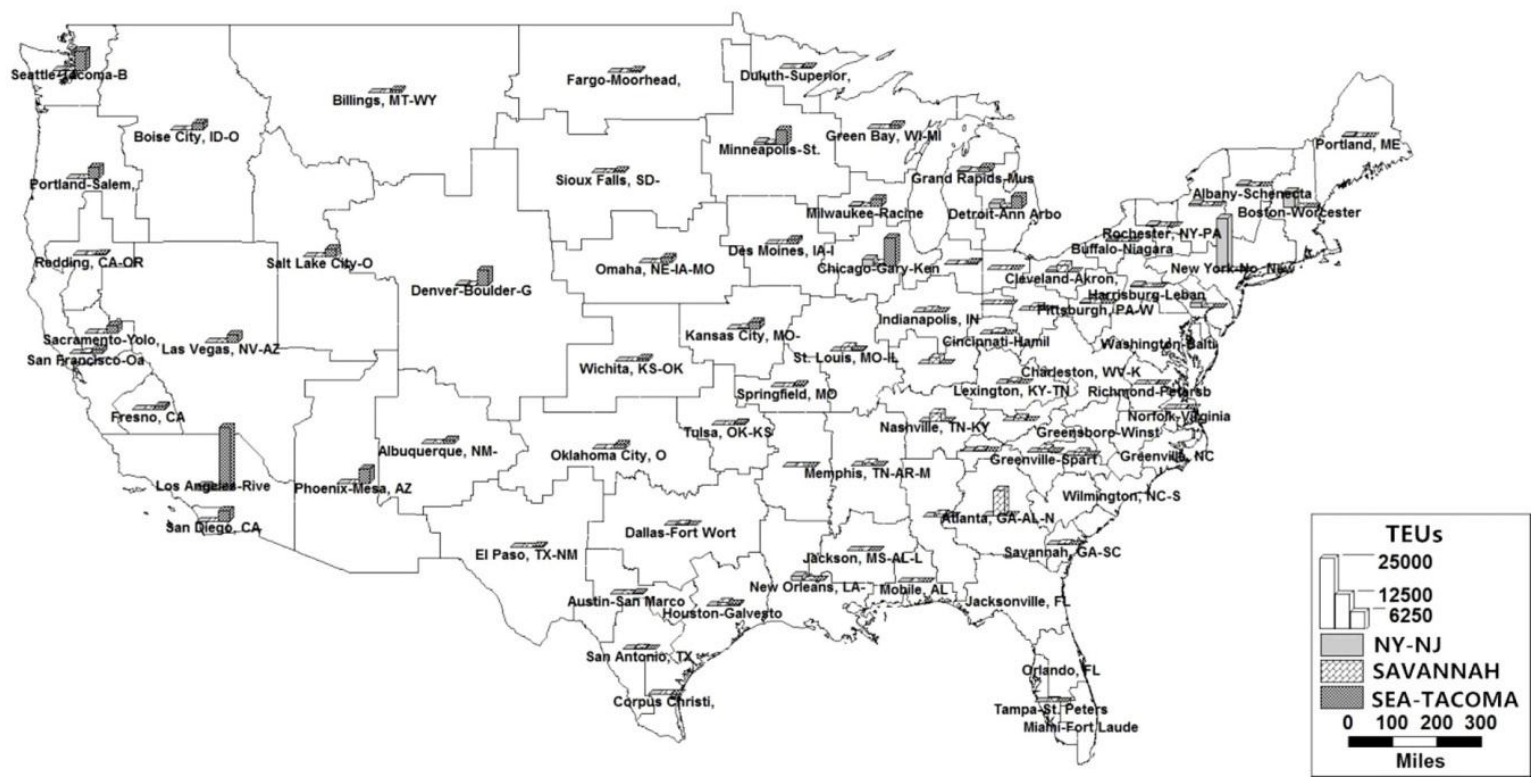

Fig. 14. Estimated imports using selected ports to TAZs when LA and LB are not available

for use.

\subsection{Example 2: Pricing changes in California.}

In November 2014, several west coast ports implemented congestion surcharges on containerized imports and exports. We assume a similar surcharge and analyze the impacts. We ignore other factors that might also influence the route selection decision of shippers, as well as the decisions of the ship operators. We suppose there is a $\$ 100 /$ TEU surcharge, assessed at each California port for both imports and exports.

Fig. 15 shows the estimated impact of this fee on traffic volume by port. The model suggests a $10 \%$ volume decrease at LA and LB, reducing volumes handled from 290,000 to 261,000 TEU per week. The decrease in volume at Oakland and San Francisco is relatively smaller at $6 \%$. About $56 \%$ of the diverted traffic is handled at Savannah, Charleston, Wilmington, and New York. Also, about 5,000 additional TEUs are estimated to be handled at Seattle and Tacoma 
ports per week. This about a $6 \%$ increase in weekly volumes.

Fig. 16 shows the percentage decrease to each TAZ from the California ports (Oakland, LA and LB). Notice that much of the decrease in the Mid-Atlantic, Northeast and the eastern portions of the Midwest, areas that are in relatively close proximity to the Port of New York and New Jersey. Prior to the imposition of the fee, these shipments entered the US via the California ports and were transported by rail large distances. In contrast, the fee has a very limited impact on flows that enter via LA and LB to destinations in the Western United States. For these goods, a $\$ 100$ fee per TEU is insufficient. Table. 4 also shows the change of rail LOS grades under these two case studies. In the case study of closure of LA and LB, around 5\% of the total length changes from near capacity to below capacity. The cost of per TEU-mile drops around 3\%. In the example of $\$ 100 /$ TEU surcharge at California ports, the impact on rail network is less obvious, only around $1 \%$ change of LOS grades as well as the cost of per TEU-mile.

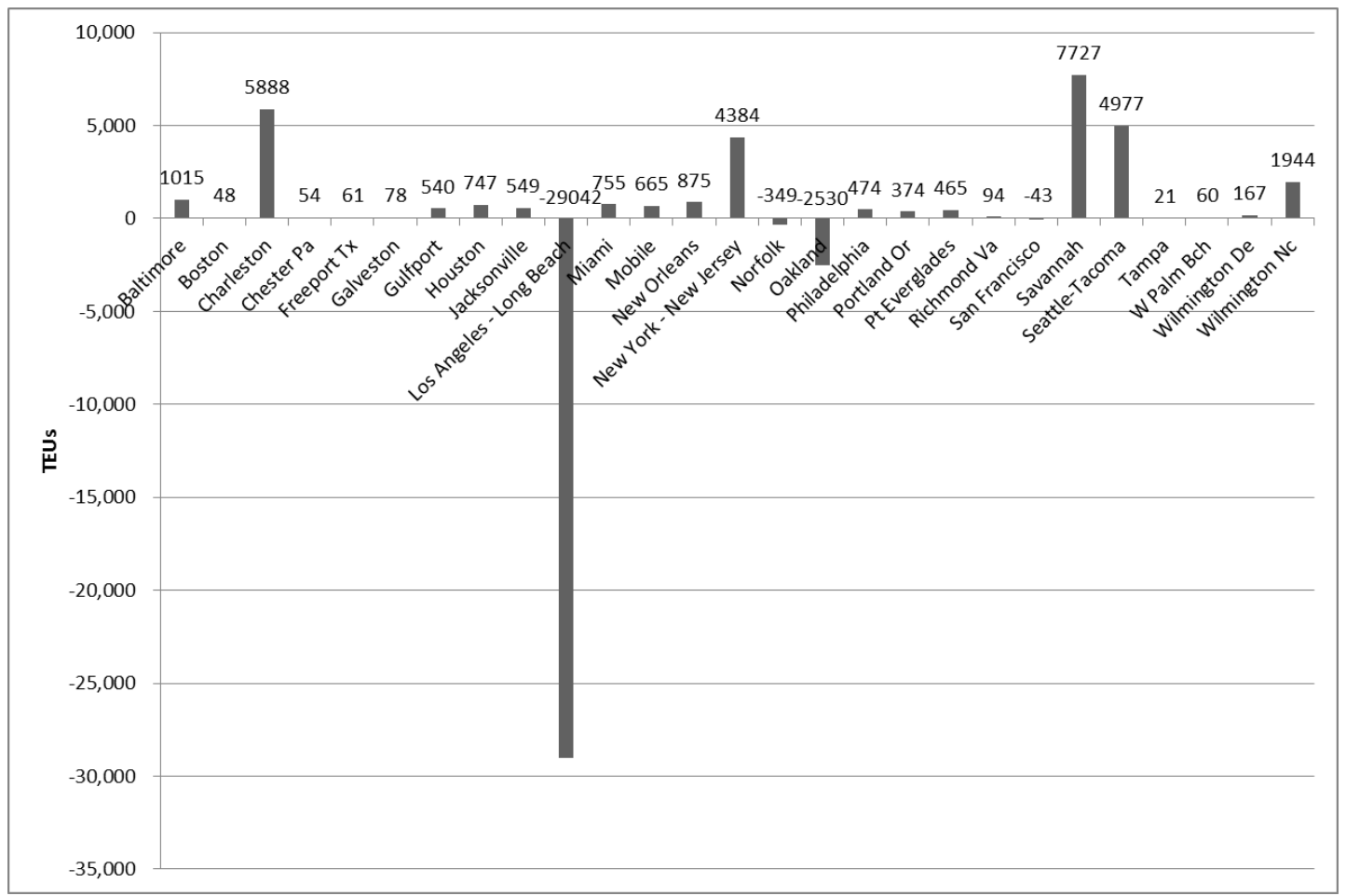


Fig. 15. Volumes change of port flows.

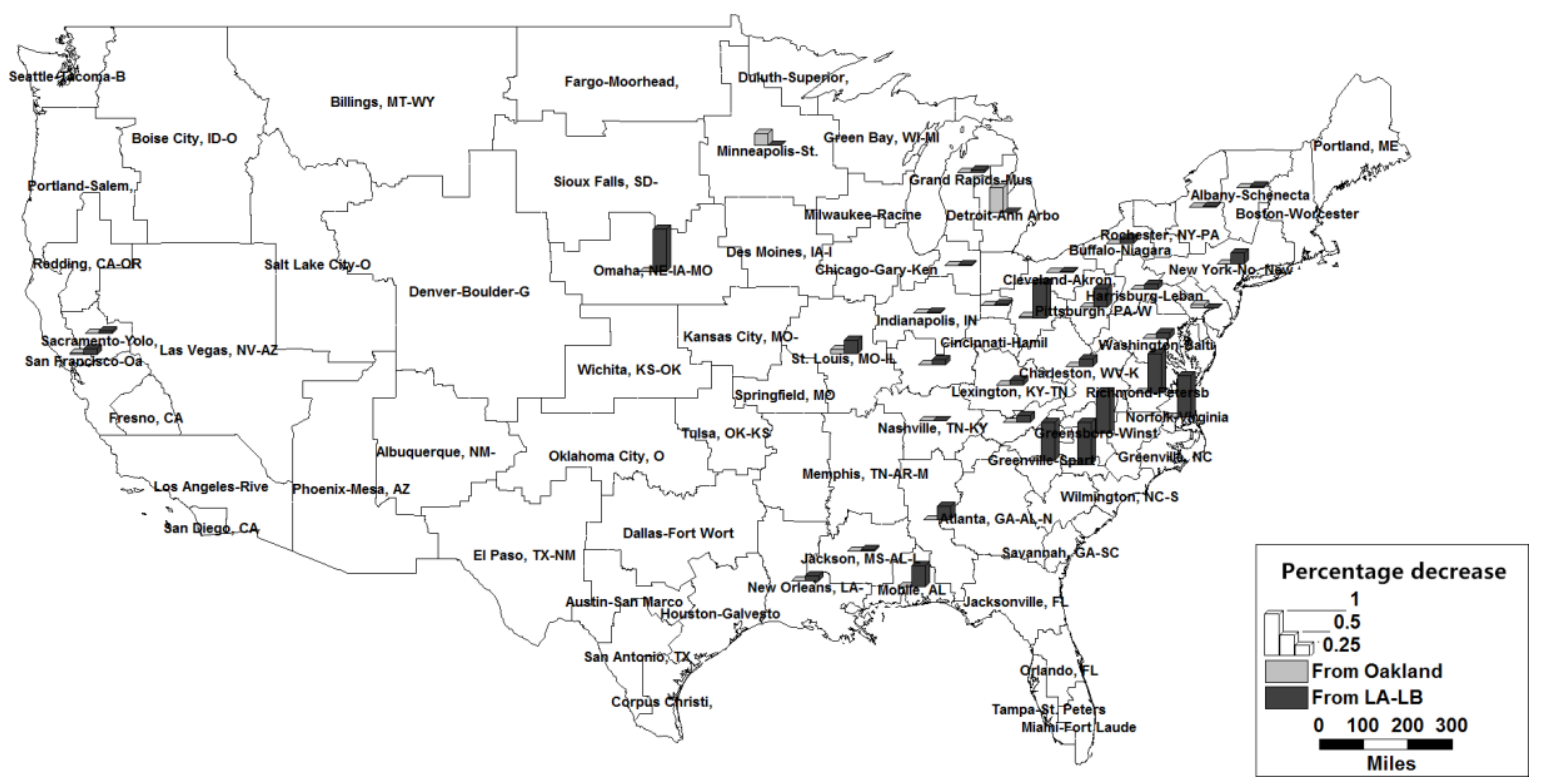

Fig. 16. Percentage decrease at Oakland and LA and LB. 


\section{Chaper 8. Conclusions}

Containerized import and export freight transportation, as well as multi-product intercity freight transportation are vital to the U.S. economy. A bi-level framework is developed for analyzing the distribution of these flows. Our model characterizes the equilibrium traffic assignment across U.S. ports, as well as the highway and railroad networks.

This dissertation makes two important contributions to the literature. First, we integrate a system optimal representation of the rail network into a multimodal user equilibrium model of freight flows in the U.S. Second, we demonstrate that this model can be used to analyze a number of national level policies of intrinsic importance, including rerouting analyses from a loss of one or more facilities, as well as to understand the impacts of the imposition of congestion pricing. It can also be used to understand the benefits of additional investments in these infrastructures. Additional research would be useful in two areas. First, it is important to integrate traffic that uses inland waterway into the model. Inland waterways are important resources for the movement of bulk commodities; however many of those waterways are susceptible to flooding. Extending this modeling environment to inland waterways would facilitate an understanding of how traffic might divert under these conditions. The second area worth investigating is extending the model to suggest how a given budget could be optimally invested to minimize transportation costs and/or to minimize environmental impacts. The U.S. freight transportation system is under increasing strain and investment has lagged, making advances in this domain particularly useful.

\section{References}

Aagaard, B. T., Blair, J. L., Boatwright, J., Garcia, S. H., Harris, R. A., Michael, A. J., . . DiLeo, J. S. (2016) Earthquake outlook for the San Francisco Bay region 2014-2043 (2327- 
6932).

Abadi, A., Ioannou, P. A., \& Dessouky, M. M. (2016) Multimodal Dynamic Freight Load Balancing. IEEE Transactions on Intelligent Transportation Systems, 17(2), 356-366.

Agrawal, B., \& Ziliaskopoulos, A. (2006) Shipper-carrier dynamic freight assignment model using a variational inequality approach. Transportation Research Record: Journal of the Transportation Research Board(1966), 60-70.

American Association of Port Authorities. (2010) North America container traffic 1990 - 2009. http://aapa.files.cmsplus.com/Statistics/CONTAINER\%20TRAFFIC\%20NORTH\%20AMERICA\%201990\% 20-\%202009.xls, accessed July 28, 2017.

Association of American Railroads. (2017) Railroads and Coal. https://www.aar.org/BackgroundDissertations/Railroads\%20and\%20Grain.pdf, accessed July 30, 2017.

Association of American Railroads. (2017) Railroads and Grain. https://www.aar.org/BackgroundDissertations/Railroads\%20and\%20Grain.pdf, accessed July 30, 2017.

Beuthe, M., Jourquin, B., Geerts, J.-F., \& a Ndjang'Ha, C. K. (2001) Freight transportation demand elasticities: a geographic multimodal transportation network analysis. Transportation Research Part E: Logistics and Transportation Review, 37(4), 253-266.

Bureau of Transportation Statistics. (2013) Pocket Guide to Transportation 2013. https://www.rita.dot.gov/bts/publications/pocket_guide to transportation/2013/system u se_and livable_communities/table_03_05, accessed July 29, 2017.

Bureau of Transportation Statistics. (2015) Freight Facts and Figures. https://www.rita.dot.gov/bts/sites/rita.dot.gov.bts/files/TSAR_2015 final_ 0.pdf, accessed July 29, 2017.

Cambridge Systematics, Inc. (2007) National Rail Freight Infrastructure Capacity and Investment Study. https://expresslanes.codot.gov/programs/transitandrail/resourcematerials-new/AARStudy.pdf, accessed July 27, 2017.

Clarke, D. B. (1995) An examination of railroad capacity and its implications for rail-highway intermodal transportation.

Crainic, T. G., Florian, M., \& Léal, J.-E. (1990) A model for the strategic planning of national freight transportation by rail. Transportation Science, 24(1), 1-24. 
de Cea Ch, J. n., \& Soto, A. (2003) A multi-modal supply-demand equilibrium model for predicting intercity freight flows. Transportation Research Part B: Methodological, 37(7), 615-640.

Dial, R. B. (2006) A path-based user-equilibrium traffic assignment algorithm that obviates path storage and enumeration. Transportation Research Part B: Methodological, 40(10), 917936.

Fan, L., Wilson, W. W., \& Tolliver, D. (2010) Optimal network flows for containerized imports to the United States. Transportation Research Part E: Logistics and Transportation Review, 46(5), 735-749.

Federal Highway Administration. (2016) Freight Quick Fact Report. https://ops.fhwa.dot.gov/publications/fhwahop16083/fhwahop16083.pdf, accessed July 29, 2017.

Friesz, T. L., Gottfried, J. A., \& Morlok, E. K. (1986) A sequential shipper-carrier network model for predicting freight flows. Transportation Science, 20(2), 80-91.

Guelat, J., Florian, M., \& Crainic, T. G. (1990) A multimode multiproduct network assignment model for strategic planning of freight flows. Transportation Science, 24(1), 25-39.

Ham, H., Kim, T. J., \& Boyce, D. (2005) Implementation and estimation of a combined model of interregional, multimodal commodity shipments and transportation network flows. Transportation Research Part B: Methodological, 39(1), 65-79.

Harker, P. T. (1986) Alternative models of spatial competition. Operations Research, 34(3), 410425.

Harker, P. T., \& Friesz, T. L. (1985) The use of equilibrium network models in logistics management: with application to the US coal industry. Transportation Research Part B: Methodological, 19(5), 457-470.

Ishfaq, R. (2013) Intermodal shipments as recourse in logistics disruptions. Journal of the Operational Research Society, 64(2), 229-240.

Jones, D. A., Farkas, J. L., Bernstein, O., Davis, C. E., Turk, A., Turnquist, M. A., . . Ostrowski, S. D. (2011) US import/export container flow modeling and disruption analysis. Research in Transportation Economics, 32(1), 3-14.

Jourquin, B., \& Beuthe, M. (1996) Transportation policy analysis with a geographic information system: the virtual network of freight transportation in Europe. Transportation research part c: emerging technologies, 4(6), 359-371.

Jourquin, B., \& Limbourg, S. (2006) Equilibrium traffic assignment on large Virtual Networks: Implementation issues and limits for multi-modal freight transport. European Journal of Transport and Infrastructure Research, 6(3), 205-228. 
Labys, W. C., \& Yang, C. W. (1997). Spatial price equilibrium as a foundation to unified spatial commodity modeling. Dissertations in Regional Science, 76(2), 199-228.

Mahmassani, H., Zhang, K., Dong, J., Lu, C.-C., Arcot, V., \& Miller-Hooks, E. (2007) Dynamic network simulation-assignment platform for multiproduct intermodal freight transportation analysis. Transportation Research Record: Journal of the Transportation Research Board(2032), 9-16.

Maia, L., \& Couto, A. (2013) Strategic rail network optimization model for freight transportation. Transportation Research Record: Journal of the Transportation Research Board(2378), $1-12$.

Miller-Hooks, E., Chen, L., Nair, R., \& Mahmassani, H. (2009) Security and Mobility of Intermodal Freight Networks: Evaluation Framework for Simulation and Assignment. Transportation Research Record: Journal of the Transportation Research Board(2137), 109-117.

Nagurney, A., Dong, J., \& Zhang, D. (2002). A supply chain network equilibrium model. Transportation Research Part E: Logistics and Transportation Review, 38(5), 281-303.

Oak Ridge National Laboratory. (2005) Railroad Network. http://cta.ornl.gov/transnet/RailRoads.html, accessed October 27, 2017.

PIERS Global Intelligence Solutions. (2006) PIERS Trade Data. http://www.piers.com/, accessed July 28, 2017.

Sheffi, Y., 1985. Urban transportation networks (Vol. 6). Prentice-Hall, Englewood Cliffs, NJ.

Surface Transportation Board (2007) Carload Waybill Sample. http://www.stb.dot.gov/stb/industry/econ_waybill.html, accessed July 28, 2017.

Tavasszy, L., Minderhoud, M., Perrin, J.-F., \& Notteboom, T. (2011) A strategic network choice model for global container flows: specification, estimation and application. Journal of Transport Geography, 19(6), 1163-1172.

The Geography of Transport Systems. (2007) Modal Split at Selected North American Container Ports. https://people.hofstra.edu/geotrans/eng/ch2en/appl2en/NA_ports_modal_split.html, accessed July 29, 2017.

Teodor Gabriel Crainic, Gilbert Laporte, (1997) Planning models for freight transportation. European Journal of Operational Research 97 (3):409-438

Uddin, M. M., \& Huynh, N. (2015) Freight Traffic Assignment Methodology for Large-Scale Road-Rail Intermodal Networks. Transportation Research Record: Journal of the Transportation Research Board(2477), 50-57. 
Wang, H., Gearhart, J., Jones, K., Frazier, C., Nozick, L., Levine, B., \& Jones, D. (2016) Estimation of an origin-destination table for US imports of waterborne containerized freight. Transportation Research Record: Journal of the Transportation Research Board(2548), 35-42.

Wilson, A. G. (1970) Inter - regional Commodity Flows: Entropy Maximizing Approaches. Geographical analysis, 2(3), 255-282.

Zhang, K., Nair, R., Mahmassani, H., Miller-Hooks, E., Arcot, V., Kuo, A., . . Lu, C.-C. (2008) Application and Validation of Dynamic Freight Simulation-Assignment Model to Large-Scale Intermodal Rail Network: Pan-European Case. Transportation Research Record: Journal of the Transportation Research Board(2066), 9-20. 